Brit. F. vener. Dis. (1968), 44, 1.

\title{
FURTHER STUDY OF ULTRATHIN SECTIONS OF

\author{
Treponema pallidum \\ UNDER THE ELECTRON MICROSCOPE*
}

\author{
BY \\ N. M. OVCINNIKOV † AND V. V. DELECTORSKIJ† \\ Central Institute for Research on Skin and Venereal Diseases of the \\ Ministry of Health of the U.S.S.R., Moscow
}

This paper presents further observations of the structure of Treponema pallidum.

\section{Method}

The examinations were made under a Soviet UEMV100 and Japanese Y-5 electron microscope. The ultrathin sections were cut with an Ardenne Westmeyer microtome and a Soviet UMVT-1 model. The methods of processing the preparations and of fixation and contrast were the same as those described in our previous communication (Ovcinnikov and Delektorskij, 1965). Special attention was paid to the negative-contrast method. As is known, a treponeme looks dark against a light ground on a photographic negative when this method is used, and consequently the positive image is the reverse. In other words, in figures in which the preparation has been treated by the negative-contrast method, treponemal features are light in colour, while the contrast substance (phosphotungstic acid) is dark. In ultrathin sections the treponemal features look dark because they have been treated with osmic acid. An advantage of the negativecontrast method is that it produces such insignificant morphological changes in the objects examined that, according to research by Valentine and Horne (1962), viruses mixed with a 1 or 2 per cent. solution of a salt of phosphotungstic acid preserve their infectivity. Specimens of $T$. pallidum were obtained from human patients with syphilis or from 7- to 8-day orchitis in rabbits infected with various strains of the treponeme (Nichols, Budapest, Central Institute for Research on Skin and Venereal Diseases/CKVI/), and cultured treponemes (Reiter, Kazan' 2 and 5, and Stavropol VII and IX strains) grown on a liver medium of $\mathrm{pH} 7.6$ with onequarter rabbit serum added were also used. The duration of culture varied in different cases.

The photo-micrographs shown in Figures 1 to 85 are concerned mainly with the morphology of the treponemes, the structure of the terminal bodies, the fibrillar apparatus, the nuclear vacuoles, and the cysts, the process of division, etc.

When examined by the dark-field method under an

* Received for publication June 5, 1967.

thead of the Department of Microbiology.

$\ddagger J u n i o r$ member of scientific staff, Department of Microbiology. ordinary optical microscope, $T$. pallidum has the appearance of a spiral structure with acuminate ends. At low magnifications under the electron microscope it can be seen that the contrast substance is far from penetrating into the body of the treponeme so that quite a lightcoloured zone can be seen round it along its whole length. Near one end the zone is thicker and wider. Some treponemes are reminiscent of a snake stretching out its neck (Fig. 2). As a result of this, the fore-part thins out while the body itself remains thick. As the treponeme moves, the thickness changes. This indicates that the body possesses a capacity for contraction.

In preparations treated by the negative-contrast method, the macro-molecular structure of the treponeme surface is clearly visible (Fig. 1, details $A$ and $B$, and Fig. 6). It is finely granular, consisting of what seem to be light-coloured verrucose processes with a dark centre. Several thin parallel bands stretch along the body of the treponeme. The authors were inclined to regard these as prints of the fibrils which passed through the site in question, but more detailed study at higher magnifications showed that, unlike the fibrils which look like a solid light-coloured line (Fig. 1A and B, F), they consist of separate polygonal particles (Fig. 1B Fll) lying parallel to each other in one direction. In some places they intersect the thick fibrils. Their position thus indicates that they more probably represent the pattern of the treponeme surface.

When examined under the dark-field optical microscope, the ends of the treponemes are sometimes somewhat acuminate, or there is an oval expansion which refracts the light more sharply. This structure, which occurs mainly at one end in young cultures, turns like a propeller in either direction. When examined under the fluorescent microscope, it fluoresces more brightly. The authors have provisionally named this structure the terminal or "head" structure. When examined under the electron microscope, the head structure in cultured treponemes is seen to be oval in shape with a neck joining it to the body of the treponeme. In pathogenic treponemes the shape is somewhat different.

In cultured treponemes (e.g. the Kazan' 2 strain), the ends are blunt, the spongy mass is surrounded by what looks like an envelope, and basal granules (B) are clearly 
visible. The structure of the terminal body is similar in the Reiter strain (Figs 12 and 14). In treponemal strains obtained from human and rabbit lesions (Nichols and Budapest strains), the head structures are thin and long with acuminate ends and the basal granules are at a considerable distance from the end. The spongy mass is drop-like in shape. The difference between cultured and pathogenic treponemes in the structure of the terminal bodies is clearly marked. The head structure in cultured treponemes is often joined to the body by means of a narrow bridge (Fig. 6K) and fibrils (Fig. 6F). This gives the impression that the head structure separates from the treponemal body together with the fibrils. Figs 2, 3, 4, 5, 49 at least give grounds for this supposition; the remnants of the head structure are encountered together with the fibrillar bundle but separate from the body of the treponeme (Figs 5, 7, 49). The "head" differs in structure from the rest of the treponeme in that there is a porous drop-like mass in front of it at either end (Figs 7, 8, 9, 10, $11,12,13,14,15,16,17)$. On either side of it are two or four basal granules (Figs 7, 8, 11, 12, 13, 14, 18, 32, 48), which are in the form of convex rings with one fibril passing through the centre. From the point of attachment on the basal granules, the fibrils pass in a bundle to another segment and sometimes wind round the body of the treponeme (Figs 7, 8, 10, 11, 14, 18, 19, 20, 21, 32); sometimes for a considerable distance they lie along one side of the treponeme. Quite often, as a result of damage, the fibrils at one end are broken off, remaining attached for the most part to the head structure; this gives the impression that they are flagella, for which indeed they have been wrongly taken (Figs $2,24,34,49,53$ ). It should be noted that the fibrillar bundle, particularly in some places, lies at a considerable distance from the body of the treponeme (Figs 1, 6, 23). This happens most often before division, when the old fibrils are shed and new ones are formed (Figs 3, 5, 49). The formation of new fibrils is seen in Fig. 30A. The shedding of old fibrils, together with part of the treponeme itself, is shown in Figs 5 and 49.

In preparations treated by the negative-contrast method, the fibrils are seen to rise above the body of the treponeme in a bundle from their point of attachment. Constant substance is found between the treponemal body and the fibrillar bundle, clearly showing the existence of a space there (Fig. 48). The fibrillar bundle is enclosed by a membrane which continues along the treponeme (Fig. 48). There are some grounds for the suggestion that the body of the treponeme, in addition to its outer wall, has a further loose and broad capsule-like membrane which covers the projecting fibrils. This cannot always be seen under the electron microscope, particularly in ultrathin sections. In most places where the fibrils pass, the treponemal envelope projects above them (Figs 43, 44, 45). Sometimes this projection is quite considerable and in some specimens looks like the keel of a ship or the beak of a bird (Fig. 47). It may be supposed that authors who have mentioned an undulating membrane in the treponeme have so described this projecting bundle of fibrils with its envelope.
Sometimes, at the base of the head structure, the junction of two treponemes can be seen (Fig. 19). In one of them the head structure is separating off and a species of lenticular body is found at the site. There is an expansion at the base of the head structure in many specimens (Figs 18sm, 21sM, and 32sM) with large dark osmiophilic sectors (SM) or a depression in the body of the treponeme (Fig. 19SM). Similar expansions are encountered in other sectors of the treponeme, in most cases projecting somewhat at one side of the site of division (Figs 30 and 30A). This obviously represents a cavity containing granules. The fact that this is a cavity communicating with the medium surrounding the treponeme can be seen from the way the contrast substance penetrates into it. It has exactly the same density as the contrast substance round it. Inside this cavity there is a lenticular or horseshoeshaped body (Figs 10, 20, 29, 30, 30AsM). On top the cavity sometimes has an entrance like that of a snail shell (Figs 28 and 30A, A). These expansions are not artefacts since they are situated in specific places and are similar in shape and content. In pathogenic treponemes, before divisions, light-coloured granular processes or spores are formed in the same way at the place of intersection of fibrils, where the anticipated division is to take place in the future (Fig. 22s).

In cultures exposed to penicillin, round, or more often irregular, dark-coloured processes or small cavities can be seen. They should be regarded as a sign of the break-up of the treponeme.

Sometimes round structures in cultured treponemes reach quite large dimensions and the contrast substance round the granules inside them is not clearly marked. The round structures shown in Figs 33s, 34s, and 35s deserve careful attention. They are oval in shape and covered with a membrane. Fig. 35 shows that the membrane has been formed from the outer wall of the treponeme. Is this a mesosome or a case of sporulation? Similar granules can be found under the membrane in treponemes, and also quite often outside it. Both in the treponemal body and outside it these granules refract light strongly and are highly fluorescent under the fluorescent microscope. They have nothing in common with the vesicular out-pouchings of the outer wall caused by disturbances of osmotic pressure.

In longitudinal sections of $T$. pallidum the outer wall can be clearly seen (Figs 33, 36, 37, 38, 43, 44, 45, 46). It consists of two electron dense layers (Fig. 46). Where fibrils pass, the outer wall projects a long way above the surface of the treponeme. At high magnifications in cross-sections it is seen to consist of large portions laid close together (Fig. 54ME). The cytoplasmic membrane also has two electron dense layers (Fig. 54MC). This suggests that the lipid components of the membrane are concentrated in the middle layer and the protein in the outer layers.

Between the outer wall and the cytoplasmic membrane lie the fibrils. Their appearance differs according to whether they are cut crosswise or longitudinally. In crosssection they look like large osmiophilic particles (Figs $55 \mathrm{~F}, 56 \mathrm{~F}, 57,59)$. More detailed study shows that in 
cross-section they are ring-shaped, and that the ring is not solid but consists of five sub-units arranged around the axis of the fibril (Fig. 54F). When our photo-micrographs of treponemal fibrils are compared with those of flagella in Salmonella typhimurium obtained by Valentine and Horne (1962), a great similarity is seen. In longitudinal sections the fibrils look like a bundle of filaments passing from one side to the other. The path of the fibrils can be seen clearly in Figs 43F, 45F, etc.

In Fig. 68, in addition to the three fibrils situated under the outer envelope (F), there are obliquely sectioned fibrils passing through the cytoplasmic membrane into the cytoplasm $\left(F^{l}\right)$.

Besides the thick fibrillar bundle there is another strand in the cytoplasm which breaks up at the ends into very tiny filaments (Figs $26,27,36$ ) which pass into the light-coloured zone of the cytoplasm (into the nuclear vacuole). Obviously this is another bundle. It may be supposed that the various types of movement of treponemes are dependent not only on the bundle of thick fibrils under the outer wall but also on another fibrillar bundle situated deeper down. The fact that treponemal movement is not due only to the bundle of "external" fibrils is confirmed by Fig. 1, which shows that the fibrillar bundle lies free but that nevertheless the spirals of the treponeme are only partly smoothed out. Over a large part of the treponeme they still remain and more of them are preserved where the fibrils stand a long way out from the body of the treponeme. If movement were due only to this bundle of fibrils then the treponemes would lose their spirals if the fibrillar bundle stood away from the body of the treponeme.

The cytoplasm consists of large particles of almost identical size-the ribosomal apparatus (Figs 26, 27, 36, $37,38,43,44,45,47,54)$. Ribosomes are, of course, the site of protein synthesis. To use the expression of Horwitz and Fors (1962), ribosomes can be "lent" to messenger ribonucleic acid (RNA) and will form the protein for the synthesis of which the RNA is coded. The particles are not randomly situated and in most cases a number of light particles surround a darker particle in the centre (Fig. 54). In cross-sections the ribosomes have the appearance of round dark granules surrounded by a lighter zone (Figs 59R, 62R). In addition to this, in both longitudinal sections (Figs $36 \mathrm{Y}, 37 \mathrm{Y}$ ) and cross-sections (Figs 64, 73), large osmiophilic granules are encountered.

The nuclear vacuole $(\mathrm{N})$ looks like a lighter polygonal or stellate zone of indefinite size or like rarefied sectors of cytoplasm. No envelope has been found in a nuclear vacuole (Figs 26, 27, 36, 58, 61, 62). Sometimes two to four dark osmiophilic granules of large size occur in the cytoplasm (Figs 36y, 37Y). So far it is difficult to say what their significance may be.

In the body of the treponeme, round structures occur which take up half the treponemal cross-section. On longitudinal section some look like two ovals one inside the other (Fig. 33s), while others have inside them concentrically arranged small granules and communicate with the space between the outer wall and the cytoplasmic membrane (mesosome) (Figs 38, 38AsM, 41sM).
Some of them are more osmiophilic and situated in the nuclear vacuole. These are also mesosomes but possibly consist of volutin (Fig. 42v). Perhaps these are structures of the same order as those shown in Figs $32 \mathrm{sm}, 34 \mathrm{~s}$, or 35s.

A longitudinal section at the level of the head structure was described in a previous paper (Ovcinnikov and Delektorskij, 1965).

In Fig. 51, which shows a section through the head structure and the first segment of the treponeme, it is possible to see the outer wall and cytoplasmic membrane, the cytoplasm obliquely cut, basal granules (B), and thick fibrils having their origin in the basal granules and passing to the other side.

Figs 52 and 53 show a tubular connecting piece (T) at the site of division. In Fig. 52 the fibrils look as though they are inside a case. In Fig. 53 they are attached by one end to the site of division.

In cross-sections the picture differs according to the part of the treponeme in which the section is taken (Figs 54 to 73, and also the cross-sections in Figs 38, $38 \mathrm{~A}$, and 39 ). In all the sections the outer wall is clearly visible, but in some photo-micrographs it cannot be seen clearly over the whole circumference. A two-layered cytoplasmic membrane can also be seen. Fibrils cannot be seen under the outer wall in all sections. They are arranged either round the treponeme in a single row or in a bundle. Their number is mostly between five and eight. Sometimes they are situated on two opposite sides or cannot be seen at all (Figs 60,66 ). The cytoplasmic membrane either covers the whole cytoplasm in the form of a dense osmiophilic two-layered structure, or covers it only on one side, being less marked on the other, or else again it turns inside the cytoplasm at one end and terminates in a dark solid expansion (Fig. 65). In the sector where the fibrils are situated under the cytoplasmic membrane, there is either an elongated osmiophilic sector (Figs 59, 64, 67) or skein-like depressions in the cytoplasm (Figs 58, 62), or else an extra envelope divided into small sections (Fig. 57w) can be seen in the cytoplasm with dark osmiophilic granules in the centre of each section. Because it is situated directly under the nuclear vacuole, which is clearly marked as a lighter stellate zone in some cross-sections, it must be supposed that this represents sectors of greatest activity. The nuclear vacuole is apparently situated not along the whole length of the treponeme but in some sectors only (Figs $58 \mathrm{~N}, 59,61$ ), since in some sections there is no such lighter zone (Figs 60,72 ), or it is only very faintly visible (Fig. 70). In the cytoplasm occasional larger granules are found in addition to the dark osmiophilic granules of the usual size (Figs 64, 73). In some sections a hook-like lighter-coloured depression can be seen with slightly elongated osmiophilic elements arranged in a single row in it (Fig. 63). Finally, in occasional cross-sections, large two-layered ring-like structures are found situated both in the centre of the cytoplasm and nearer to the periphery (Figs 38 (cross-section), 38A, 39, 71). It is difficult to say what the significance of either structure is. The balance 


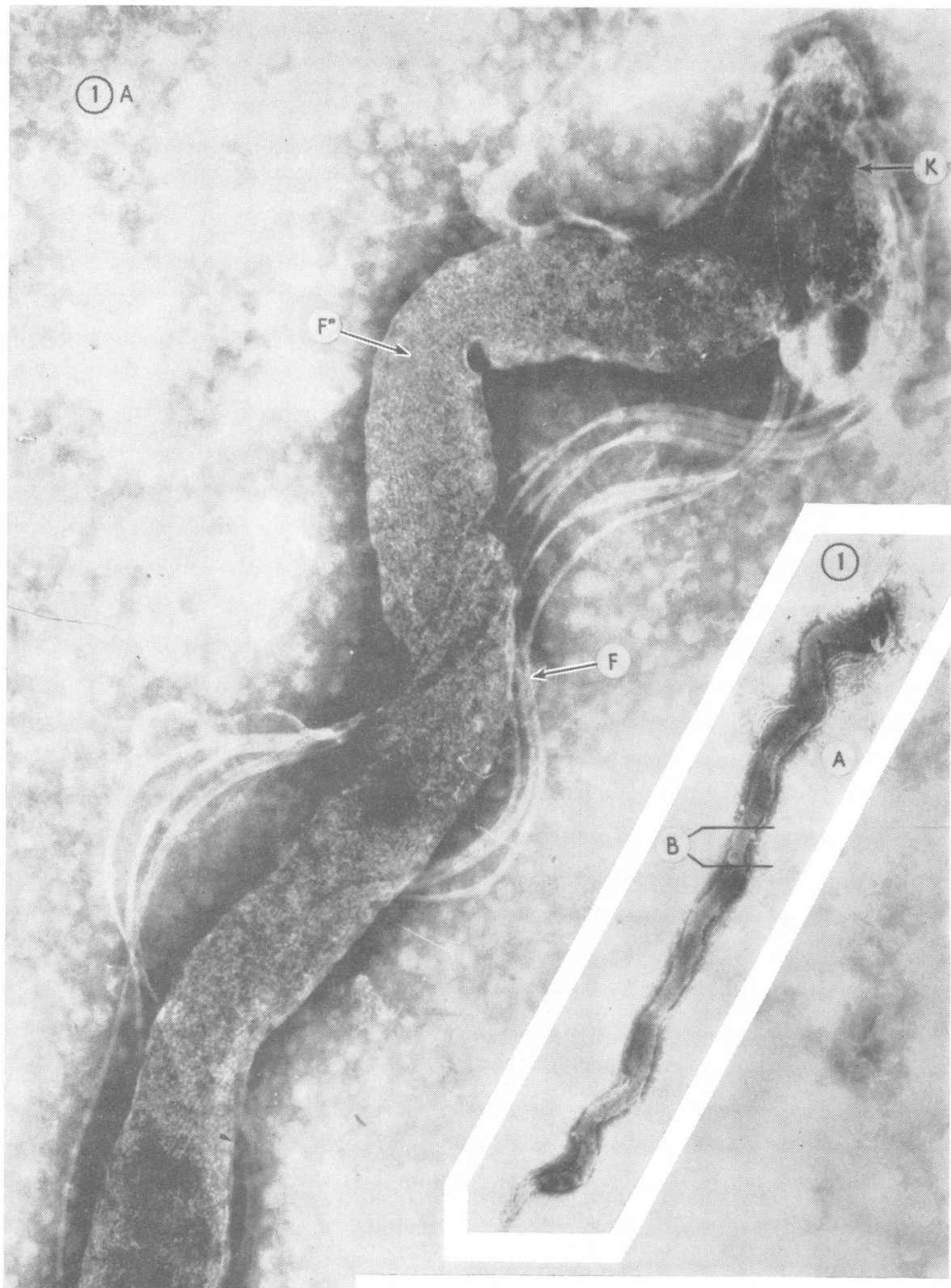

FIG. 1.-Kazan' 2 strain, 14 days' growth on Tarozzi medium with one-third rabbit serum added. Negativecontrast method. $\times 45,000$.

A.-Detail of Fig. 1. Photographic magnification $\times 100,000 ; \mathrm{K}$-head structure; $\mathrm{F}$-fibrils; $\mathrm{F}-$-thin parallel lines along the treponeme.

B.-Detail of Fig. 1. Photographic magnification $\times 445,000$. The surface structure of the treponeme is visible, consisting of polygonal particles. $\mathrm{F}-$ parallel thin bands along the body of the treponeme; Nnucleus, mesosome ?; F-fibril. 


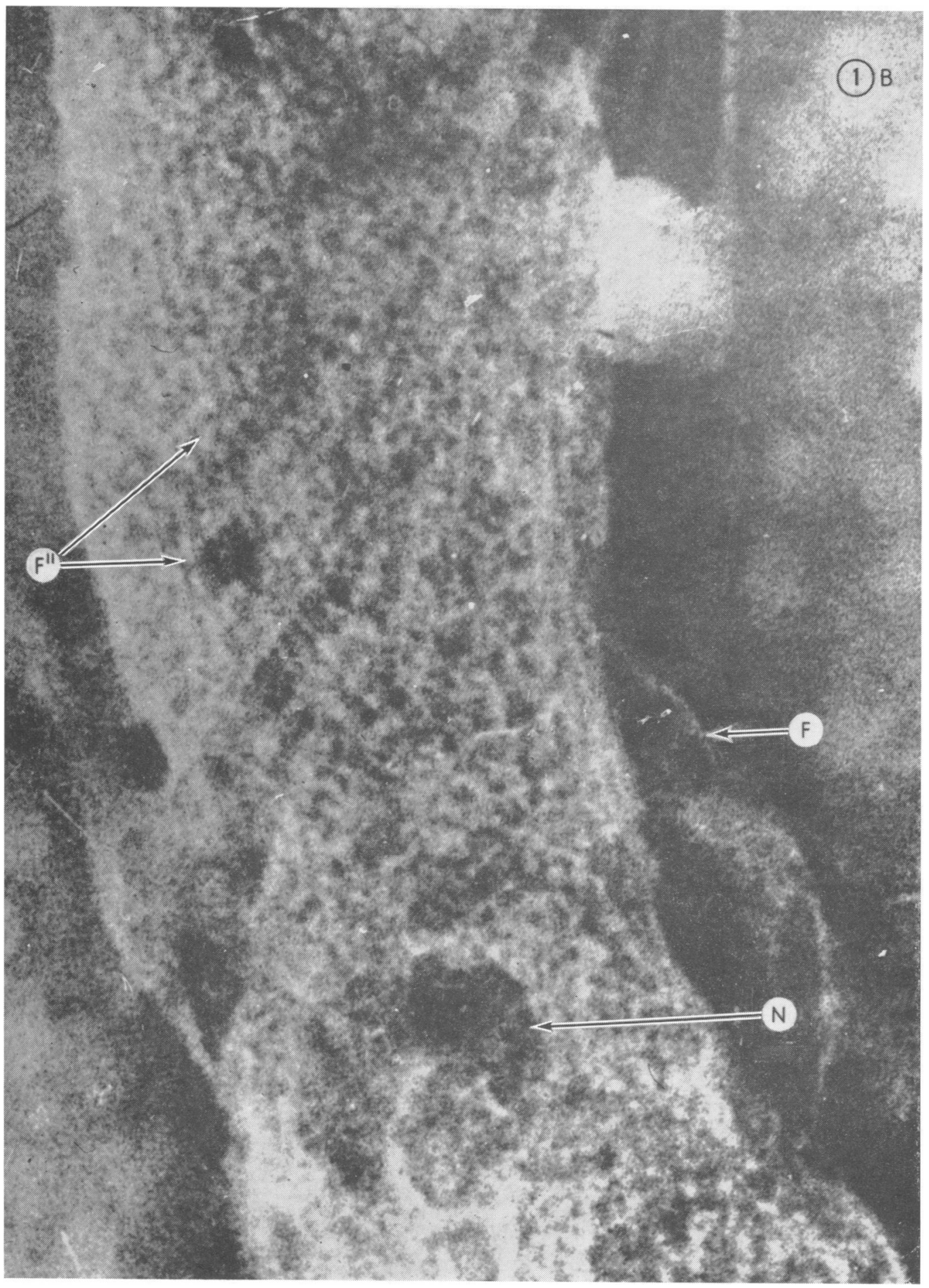




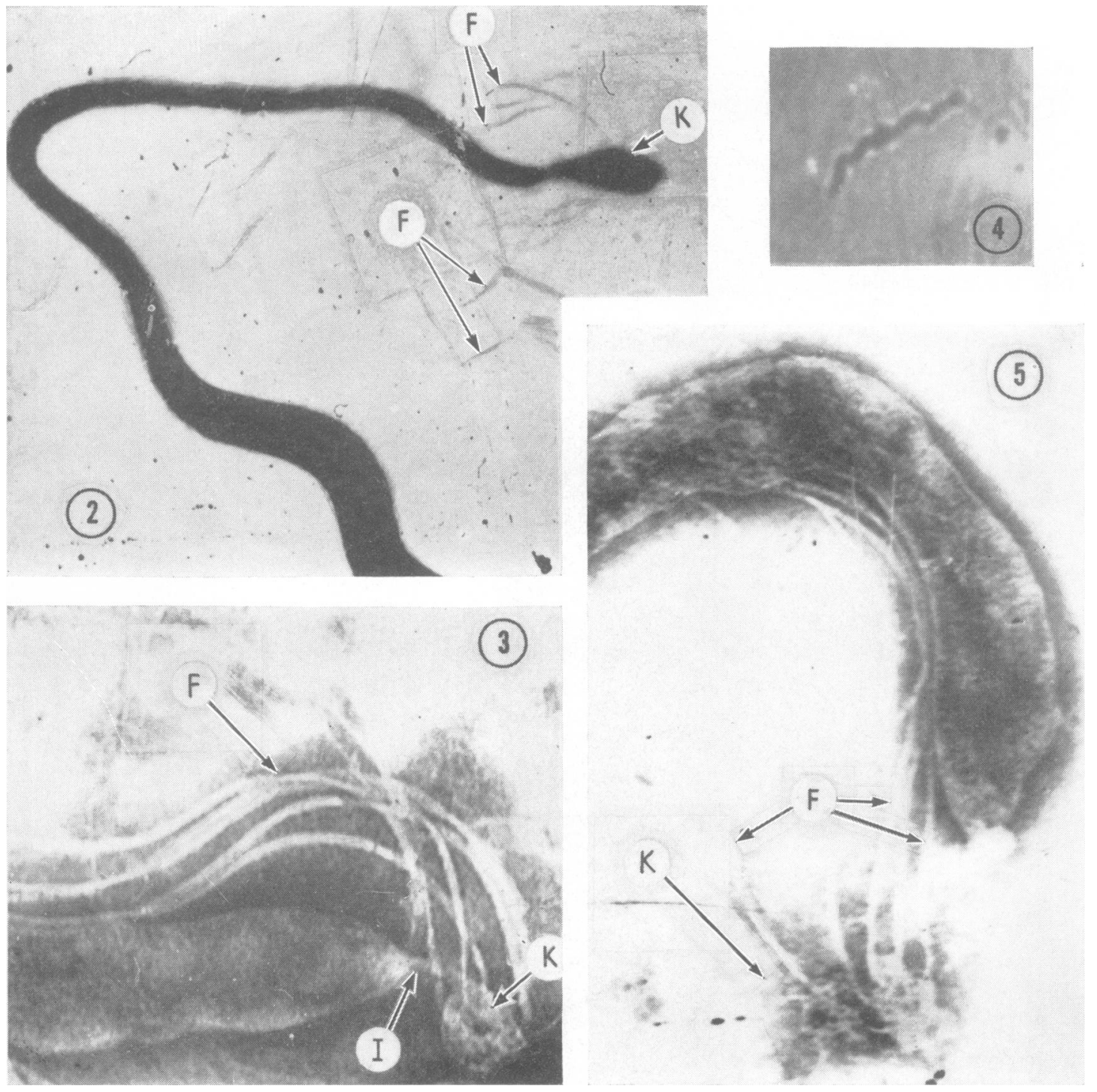

FIG. 2.-Kazan' 2 strain, 14 days' growth. Electronmicroscope magnification $\times 10,000$. $\mathrm{K}$-head structure and $a$ thinner part adjoining it, the rest of the treponeme being twice as thick; $\mathrm{F}$-fibrils.

FIG. 3.-Kazan' 2 strain, 14 days' growth. Negative contrast-method. Magnification $\times 70,000$. $\mathrm{k}$-head structure breaking away as it were from the body of the treponeme but connected with it by a narrow isthmus (I) and fibrils (F).

FIg. 4.-Head structure breaking off, as seen under the light microscope. Objective-apochromatic lens $1 \cdot 30$; ocular $10 \times$. Silvered by Morozov method.

Fig. 5.-Same as Fig. 3, but the head structure (k), together with the fibrils (F), has torn away and has apparently undergone degeneration. 


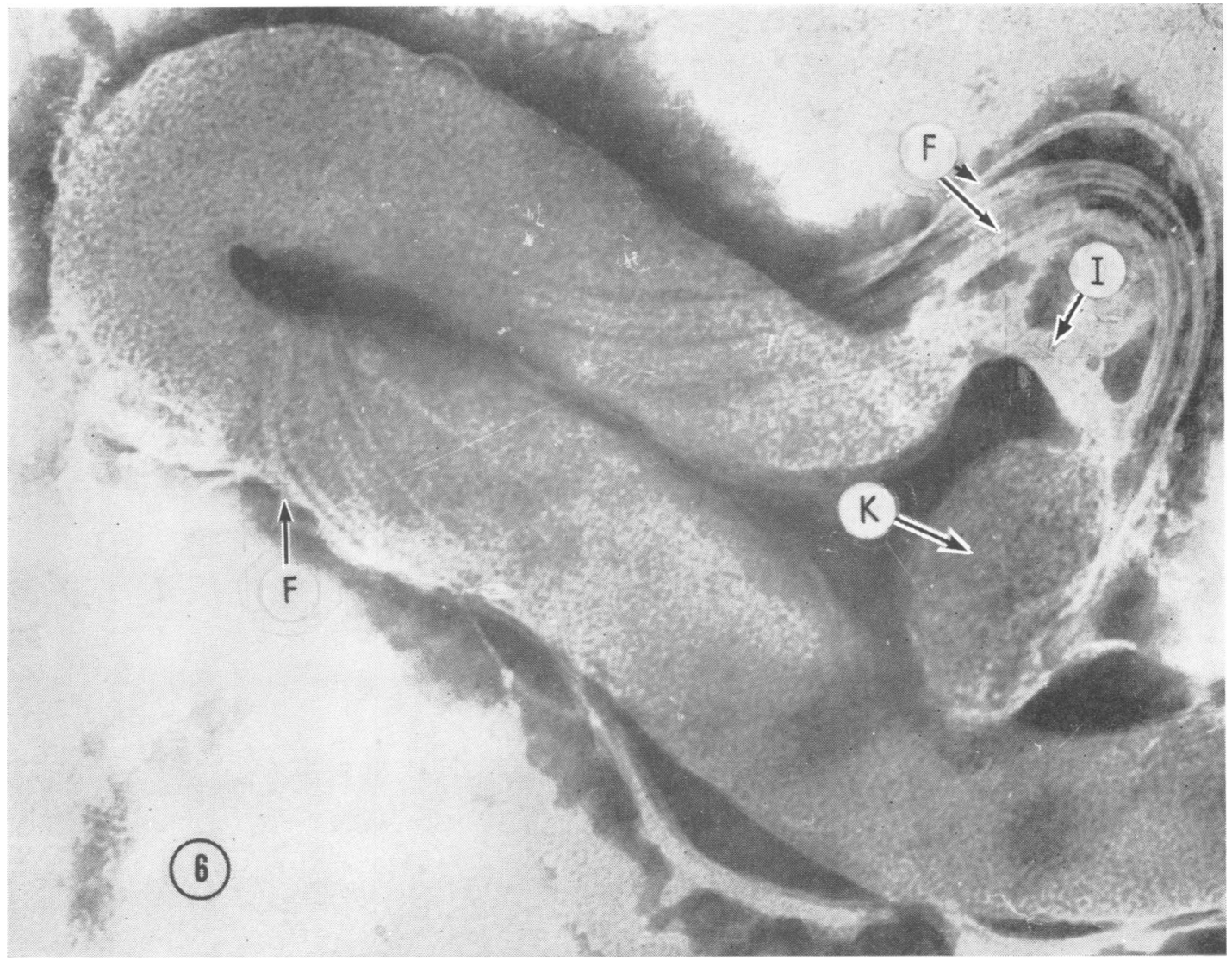

Fig. 6.-Kazan' 2 strain, 14 days' growth. Negativecontrast method. Photographic magnification $\times 300,000$. $\mathrm{k}$-head structure with a narrow isthmus (I) and fibrils (F) joining it to the treponemal body. The surface structure of the treponeme, consisting of polygonal particles, is clearly visible. 

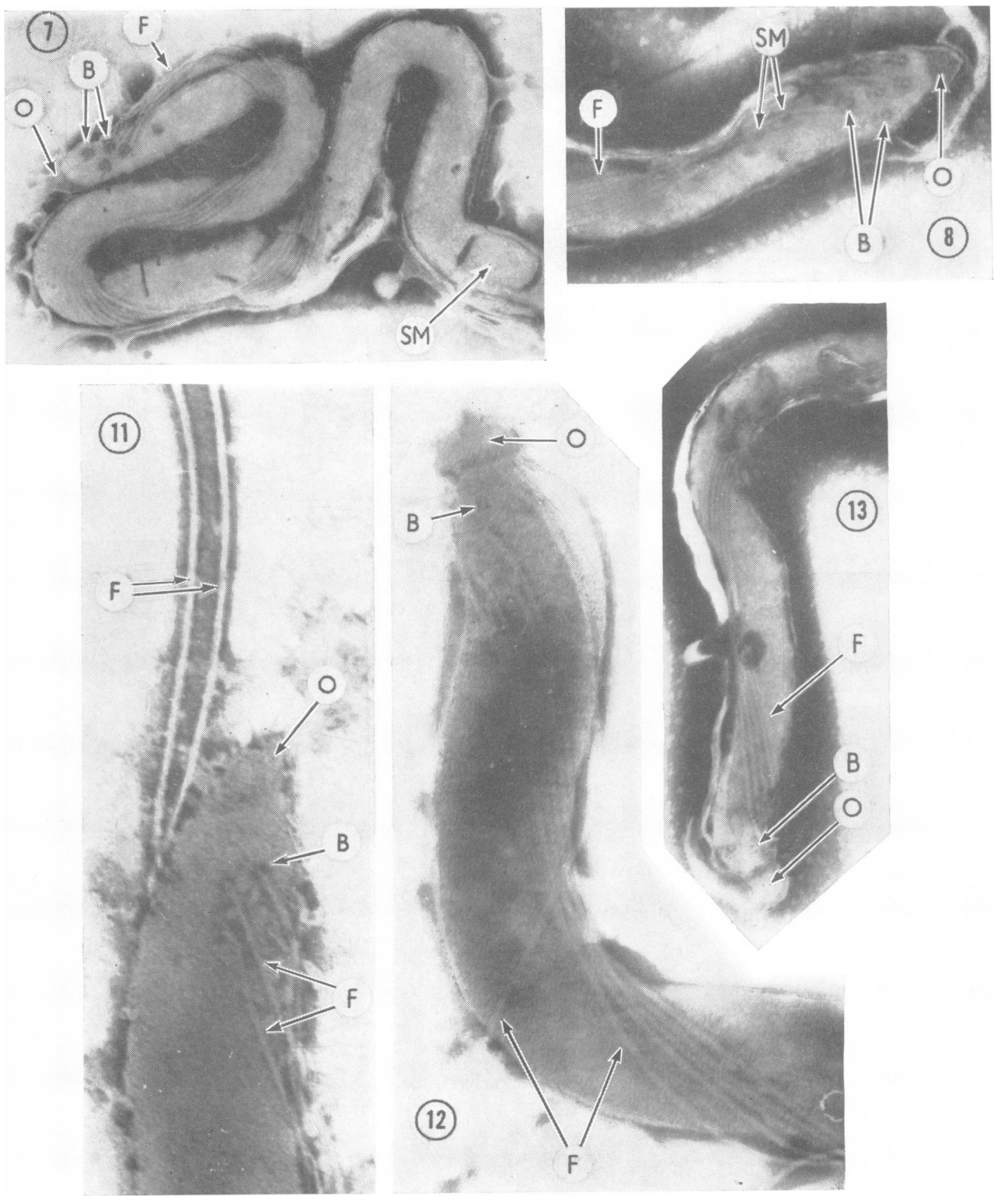

FIG. 7.-Kazan' 2 strain, 14 days' growth. Negativecontrast method. Basal granules (B), fibrils (F), a spongy mass (O), and a granule-like structure (SM) are all clearly visible.

Fig. 11.-Kazan' 2 strain, 14 days' growth. Fibrils (F), basal granules (B), and spongy mass (O) are clearly visible. The fibrils run in different directions from the site of division.

FIG. 8.-Kazan' 2 strain, 14 days' growth. Negativecontrast method. Basal granules (B), fibrils (F), a spongy mass (o), and a granule-like structure (SM) are all clearly visible.

Fig. 12.-Reiter strain, 7 days' growth. Negativecontrast method. Key as Fig. 11.

FIG. 13.-Kazan' 2 strain, 14 days' growth on Tarozzi medium. o-spongy mass of drop-like shape; $\mathrm{B}$-basal granules; F-fibrils. 

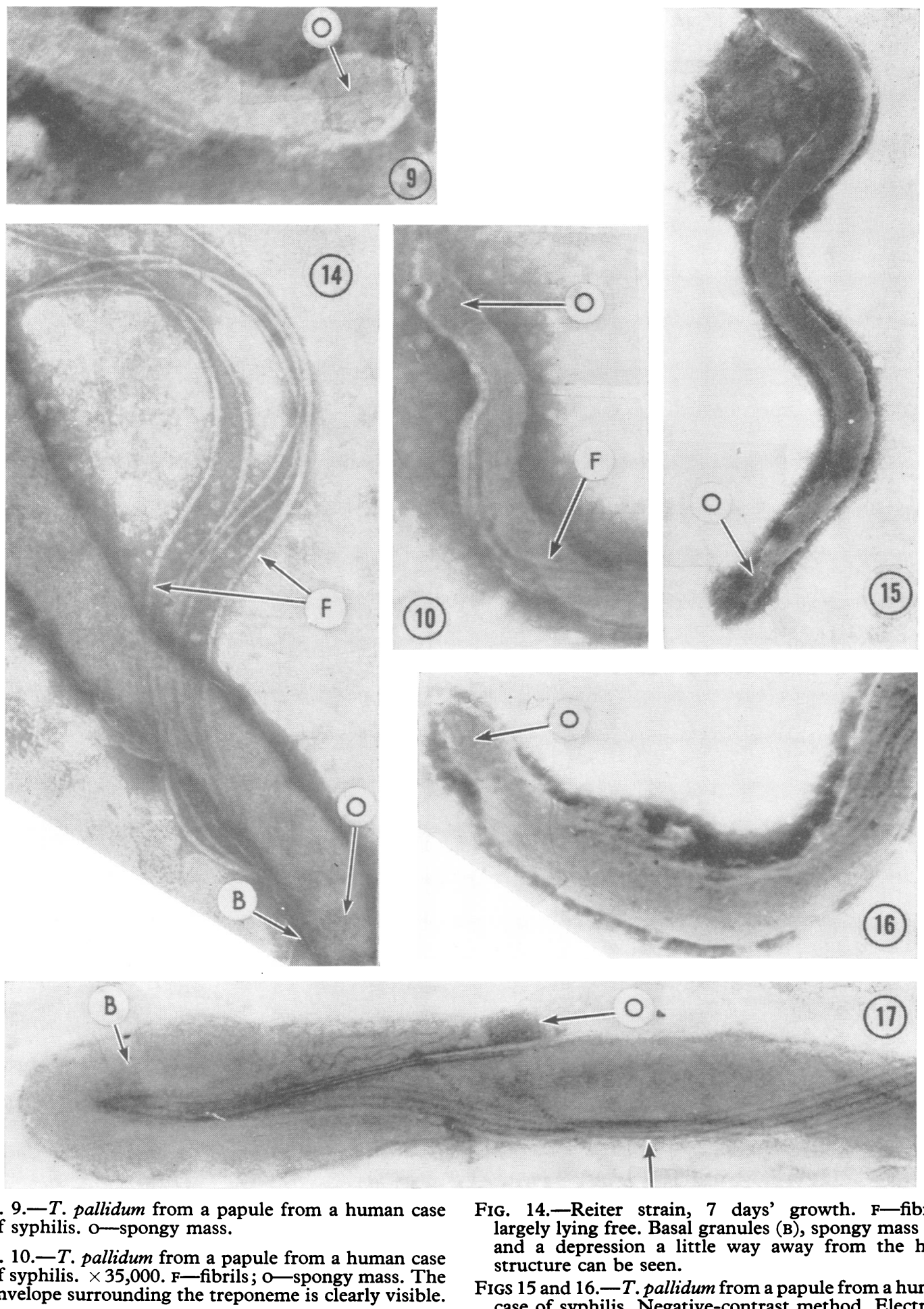

Fig. 9.- T. pallidum from a papule from a human case of syphilis. o--spongy mass.

Fig. 10.-T. pallidum from a papule from a human case of syphilis. $\times 35,000$. F-fibrils; o-spongy mass. The envelope surrounding the treponeme is clearly visible.

FIG. 17.-Nichols strain from a 7-day rabbit orchitis. Key as in Fig. 14.

FIG. 14.-Reiter strain, 7 days' growth. F-fibrils, largely lying free. Basal granules (B), spongy mass (O), and a depression a little way away from the head structure can be seen.

Figs 15 and 16.-T. pallidum from a papule from a human case of syphilis. Negative-contrast method. Electronmicroscope magnification $\times 42,000$. o-spongy mass of drop-like shape. 

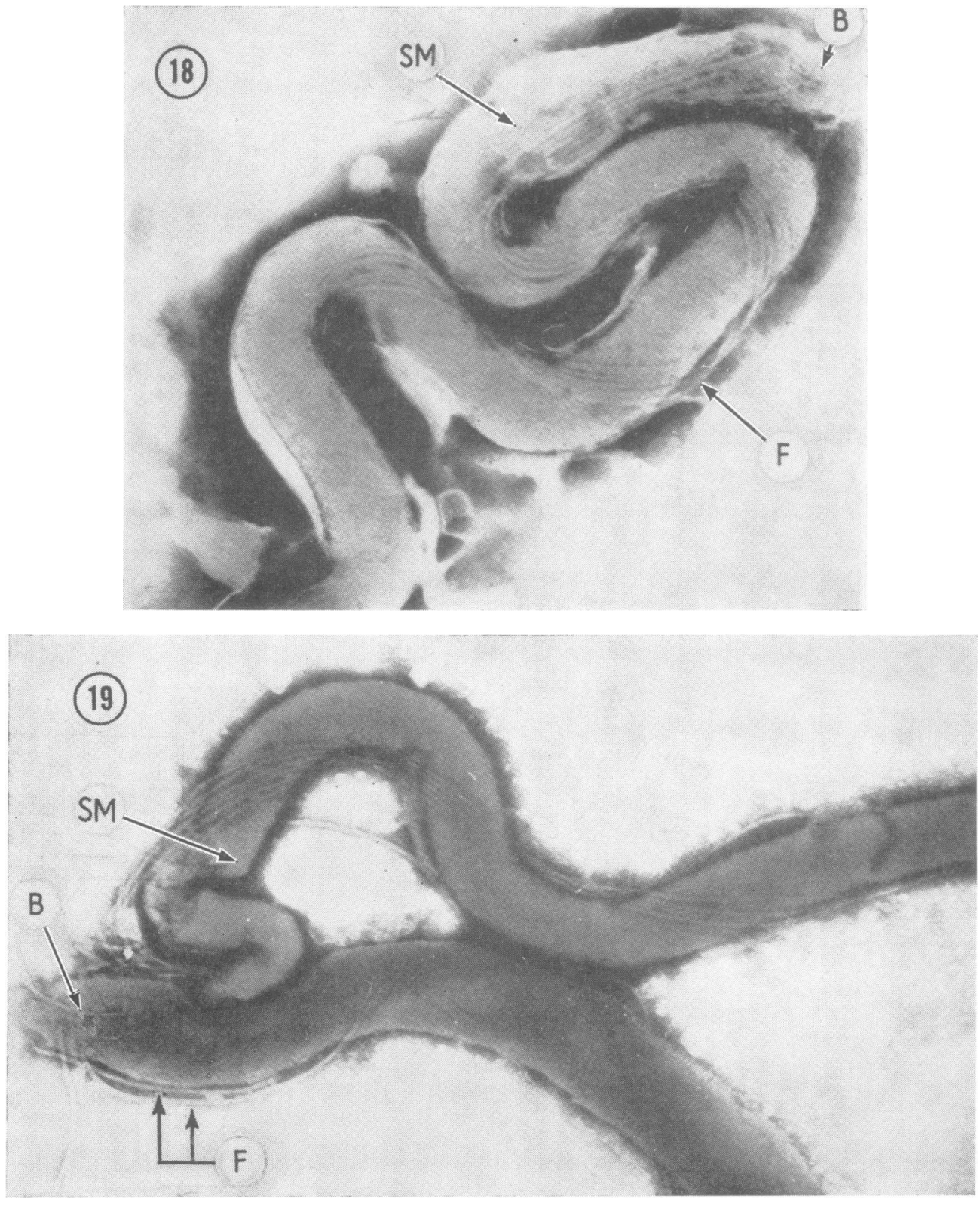

Figs 18, 19, and 21.-Kazan' 2 strain, 14 days' growth. Negative-contrast method. Electron-microscope magnification $\times 60,000$. $\mathrm{B}$-basal granules; $\mathrm{F}$-fibrils; SM-expansion with osmiophilic granules. 

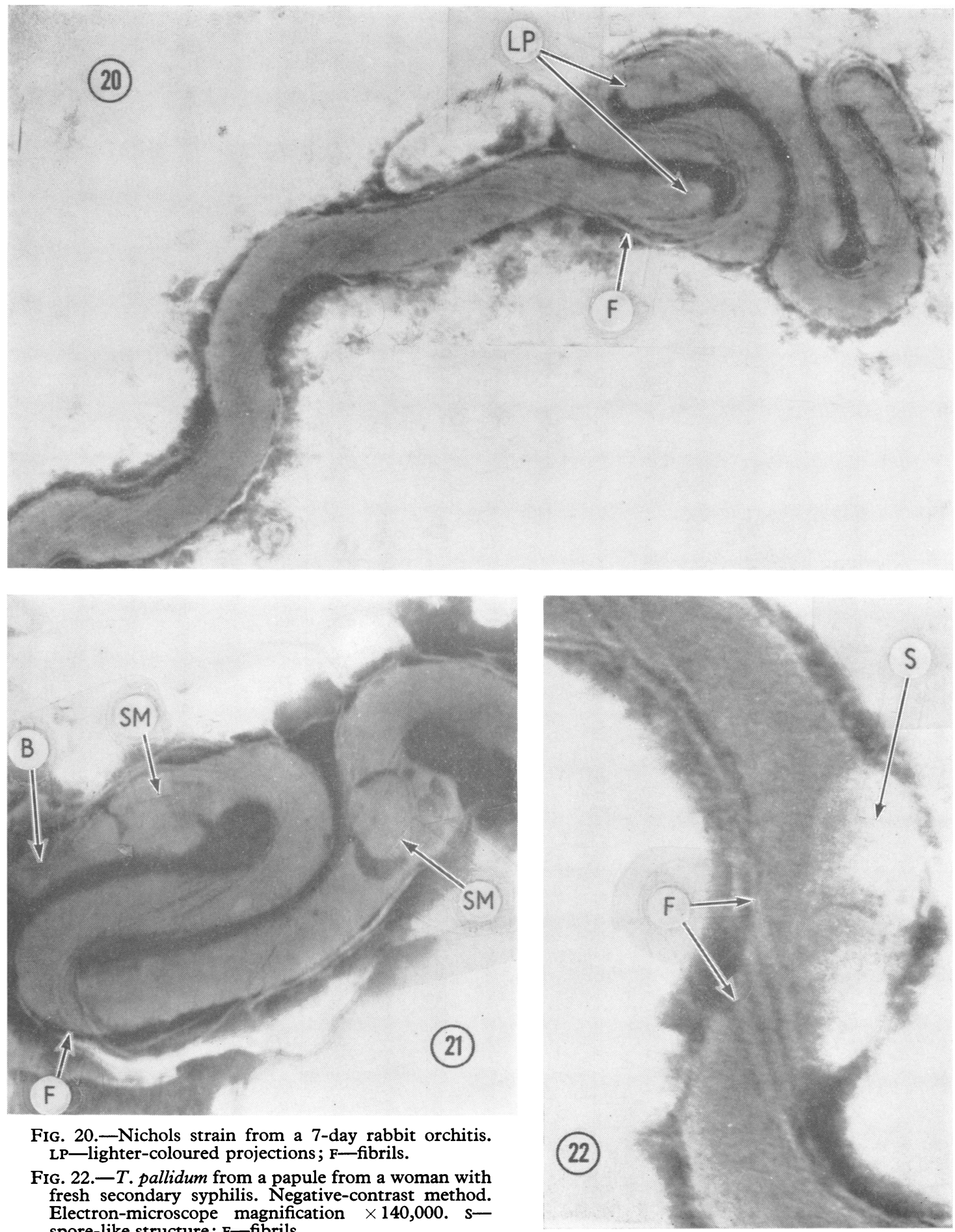

FIG. 20.-Nichols strain from a 7-day rabbit orchitis. LP-lighter-coloured projections; F-fibrils.

FIG. 22.-T. pallidum from a papule from a woman with fresh secondary syphilis. Negative-contrast method. Electron-microscope magnification $\times 140,000$. $s-$ spore-like structure: F-fibrils. 

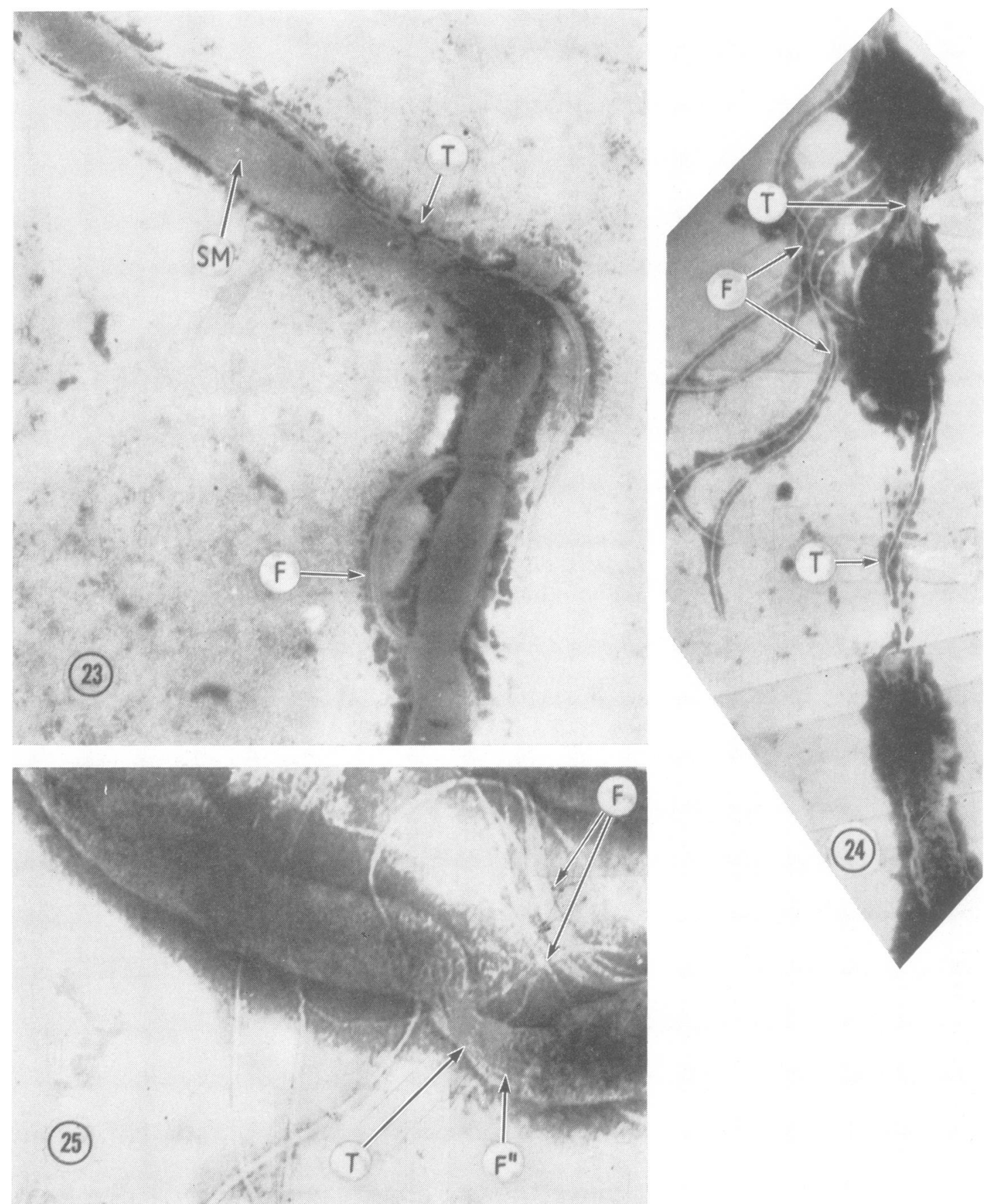

Fig. 25.-Kazan' 2 strain, 14 days' growth. Negative-

Figs 23 and 24.- Reiter strain, 7 days' growth on Tarozzi medium with rabbit serum added. Electron-microscope magnification $\times 58,000$. $\mathrm{T}$ - site of division, remnants contrast method. At the site of division ( $T$ ) deepplaced fibrils $\left(F^{\prime \prime}\right)$ and old fibrils $(F)$ can be seen. of bridge; F-old fibrils; SM-granule-like body. 

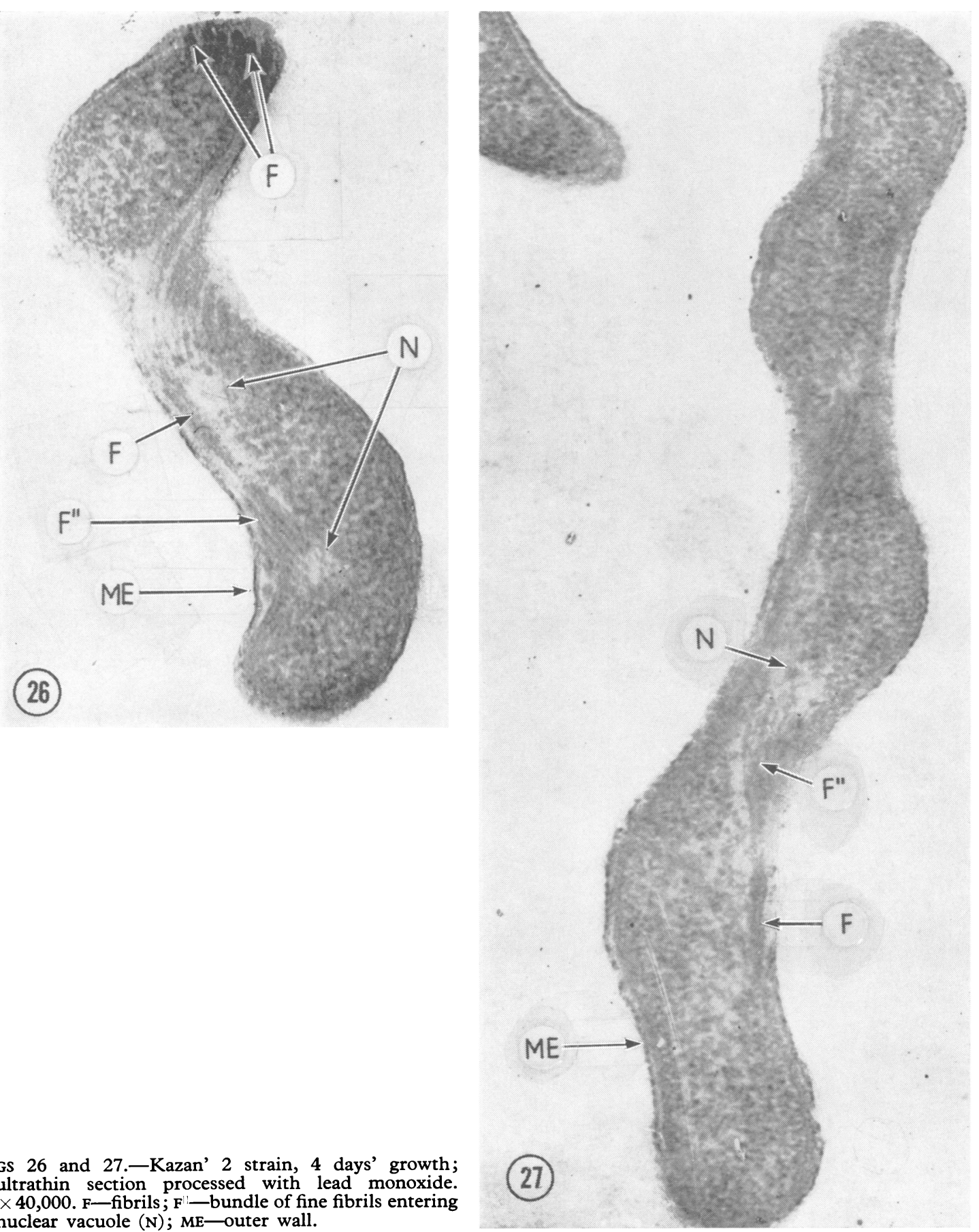

FIgs 26 and 27.-Kazan' 2 strain, 4 days' growth; ultrathin section processed with lead monoxide. $\times 40,000$. F-fibrils; $F-$ bundle of fine fibrils entering nuclear vacuole $(\mathrm{N})$; ME-outer wall. 

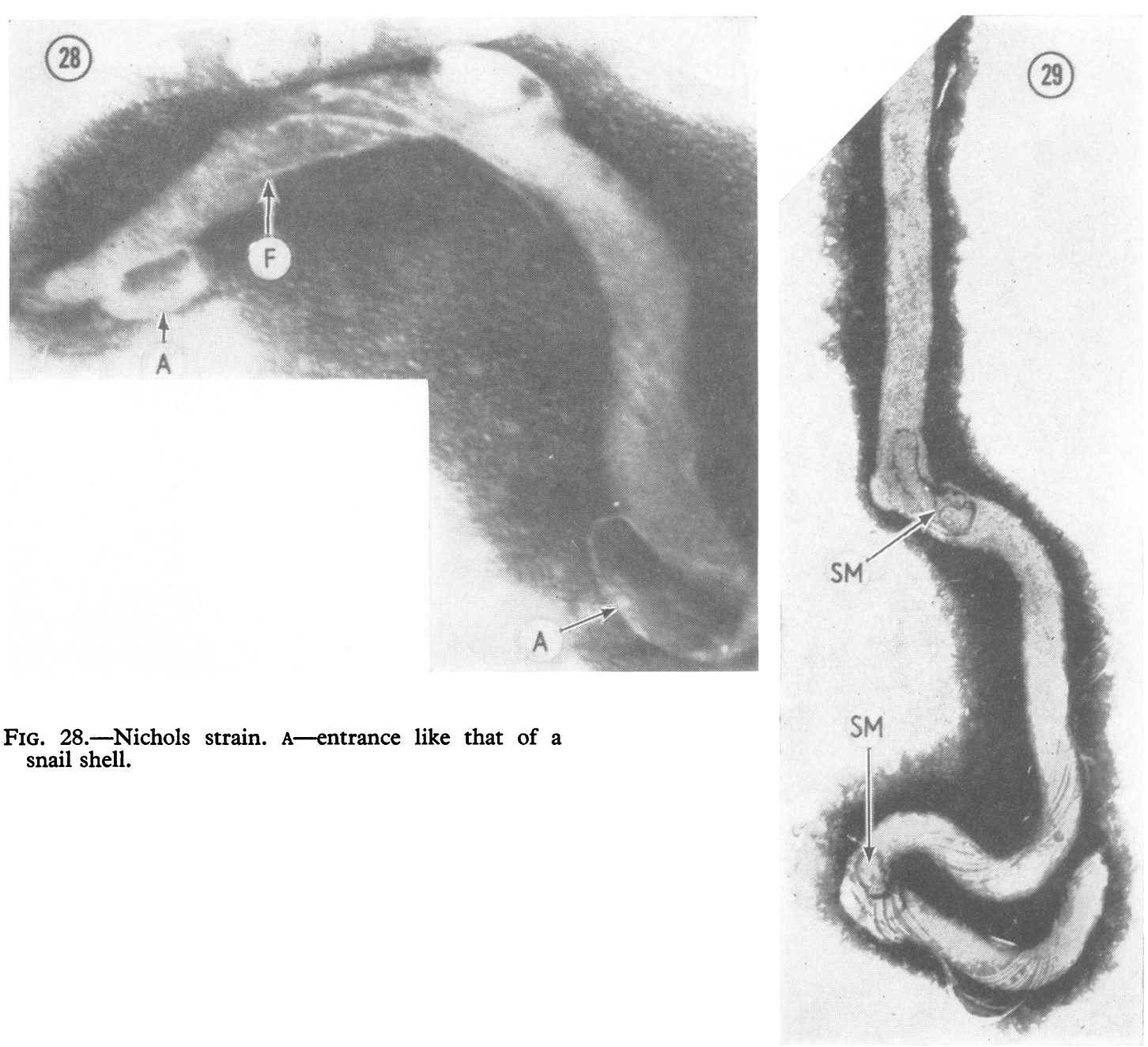

FIG. 28.-Nichols strain. A-entrance like that of a snail shell.

FIGs 29 and 30.-Kazan' 2 strain. Negative-contrast method. $\times 37,000$. SM-Granule-like inclusion, mesosome ?; $\mathrm{T}$ - site of division.

A.-Detail of Fig. 30. $\times 100,000$. A-Entrance like that of a snail shell.

FIG. 31.-Nichols strain on a medium with 0.01 units penicillin added. 7 days' growth. Electron-microscope magnification $\times 45,000$. New fibrils $(F)$ interweaving at site of division $(T)$. 

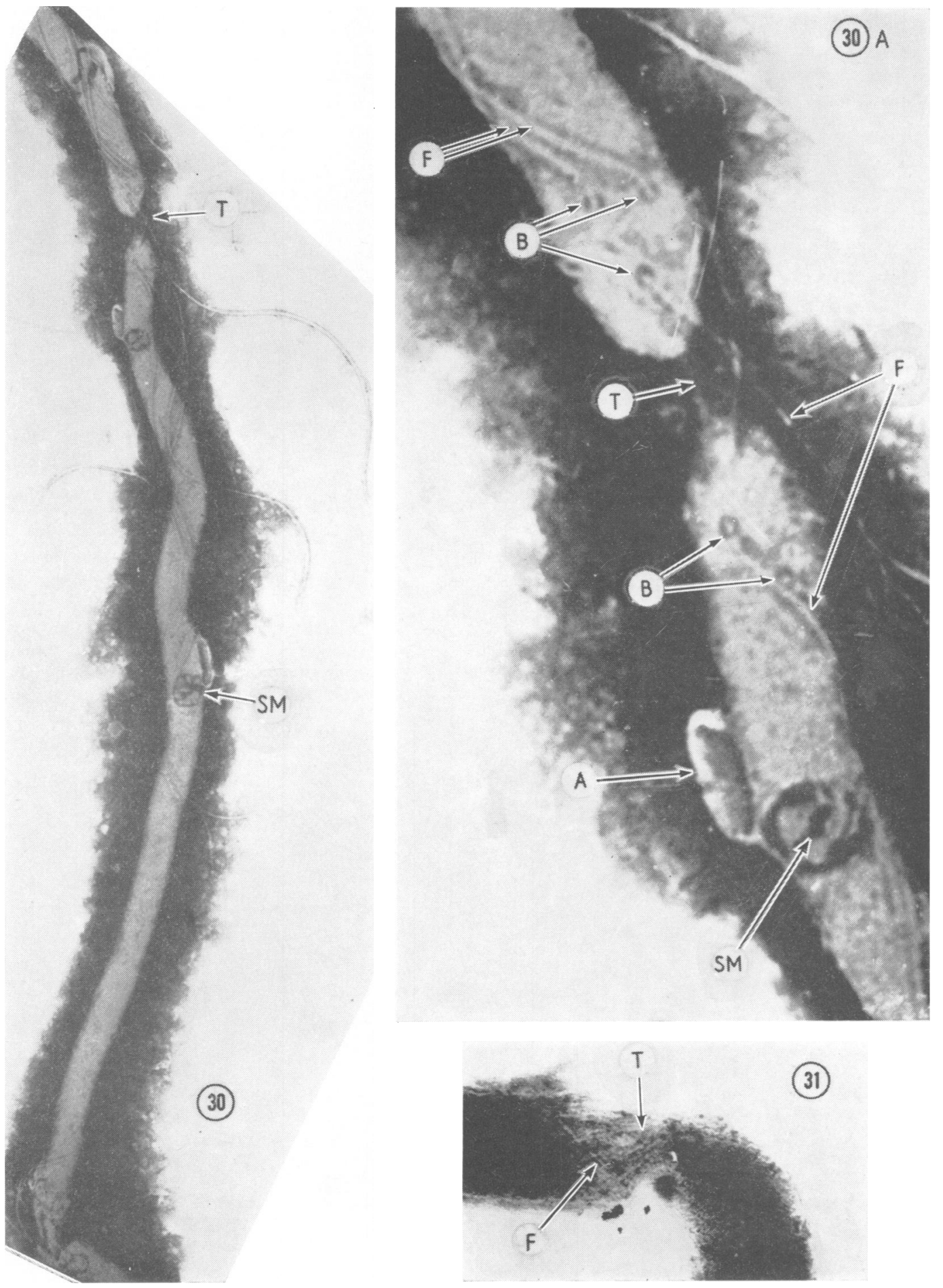

(31)

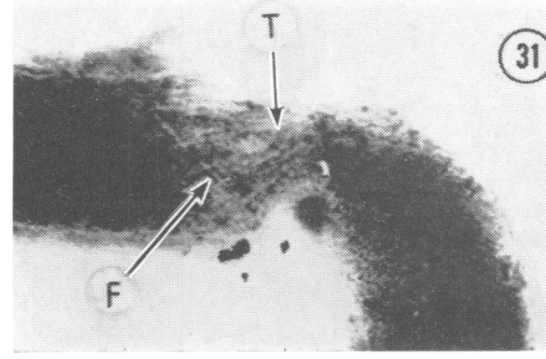



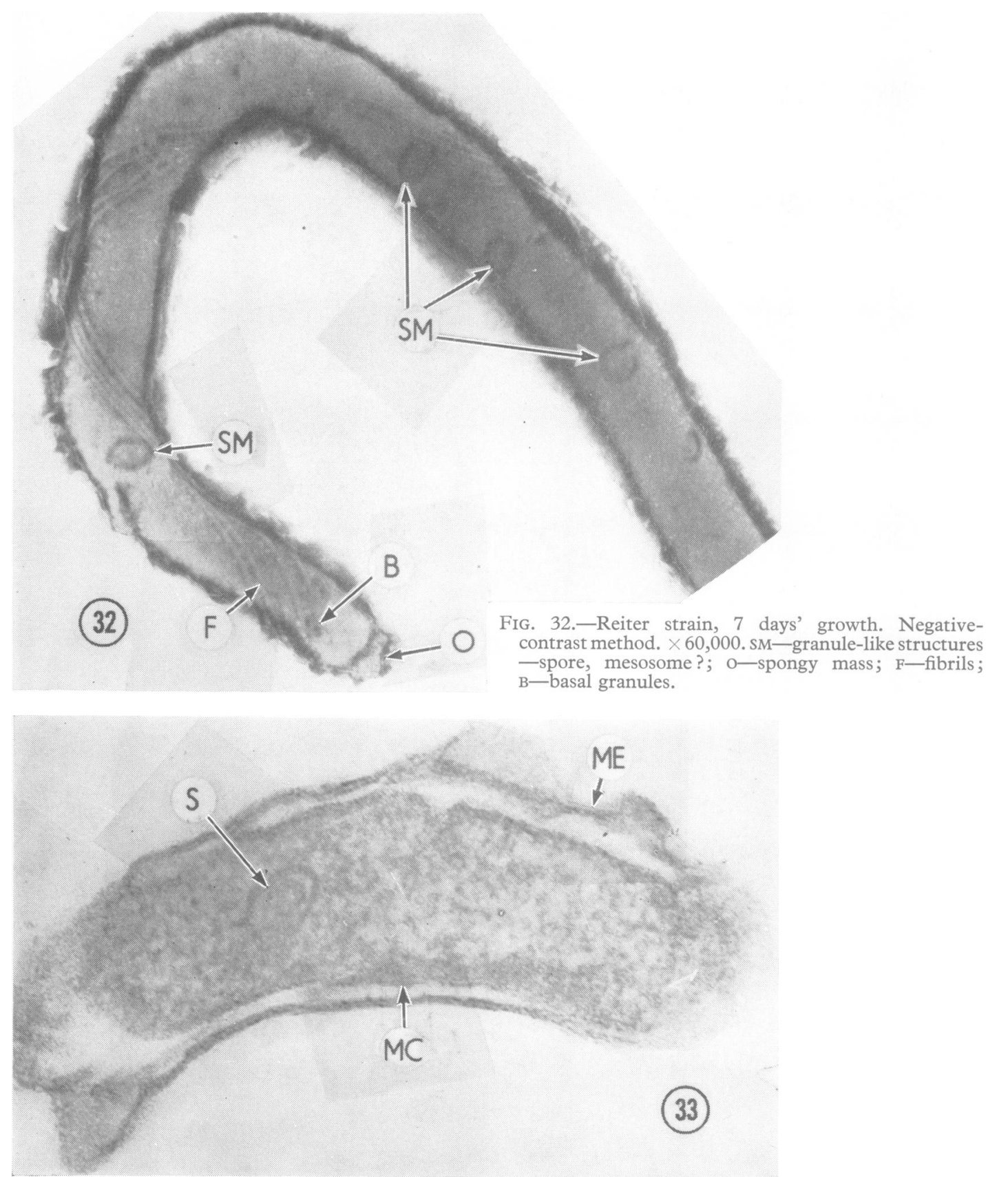

FIG. 33.-Kazan' 2 strain, 4 days' growth; ultrathin longitudinal section processed with uranyl acetate. $\times 50,000$. $s$ - ring-like inclusion (mesosome); MEouter wall; $M C$ - cytoplasmic membrane. 

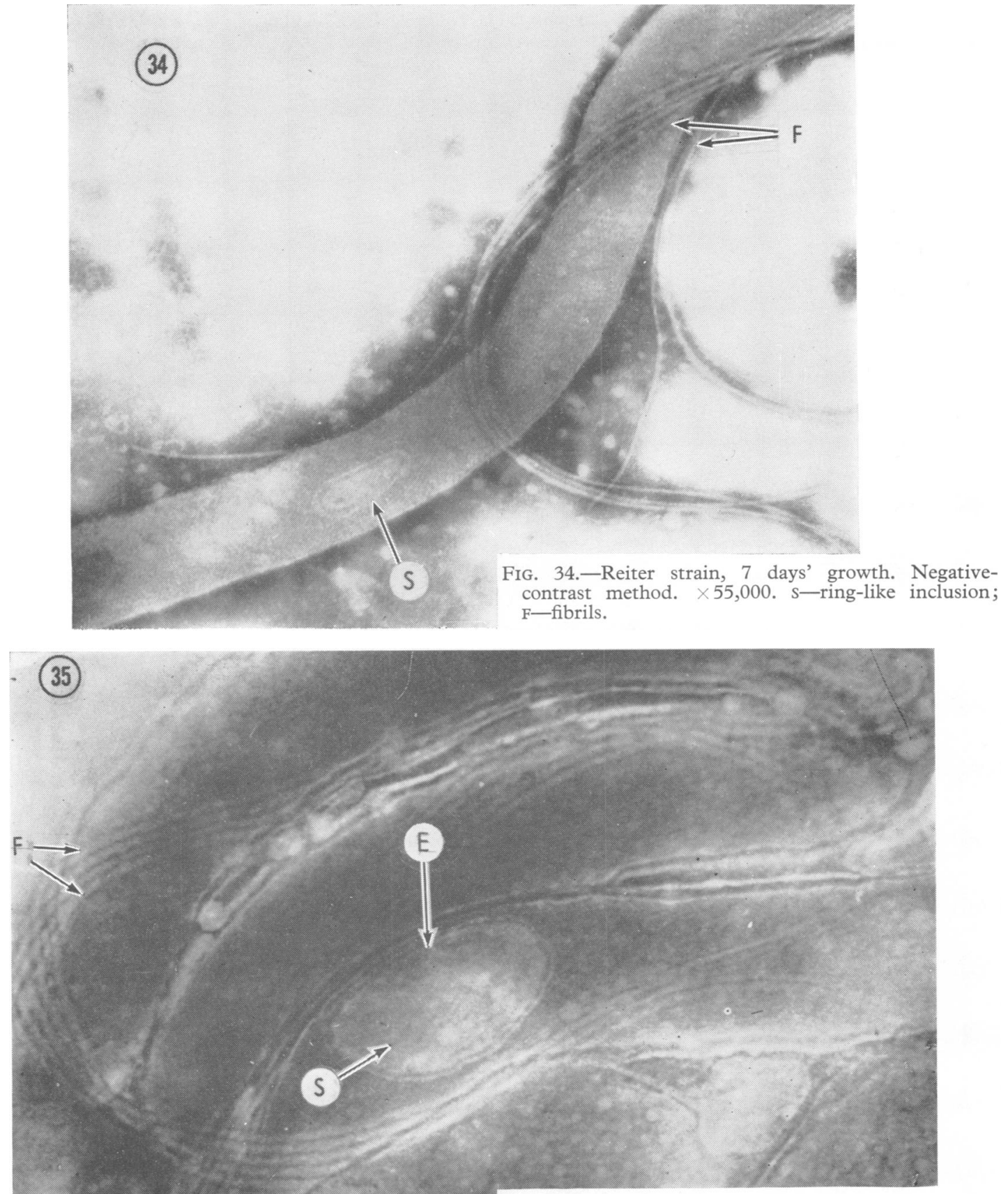

FIG. 35.-Kazan' 2 strain, 4 days' growth. Negativecontrast method. $\times 55,000$. Part of cyst-like structure. Fibrils (F) can be clearly seen. S-ring-like inclusion, the membrane of the inclusion being formed from the outer wall of the treponeme. An entrance can be seen (E). 

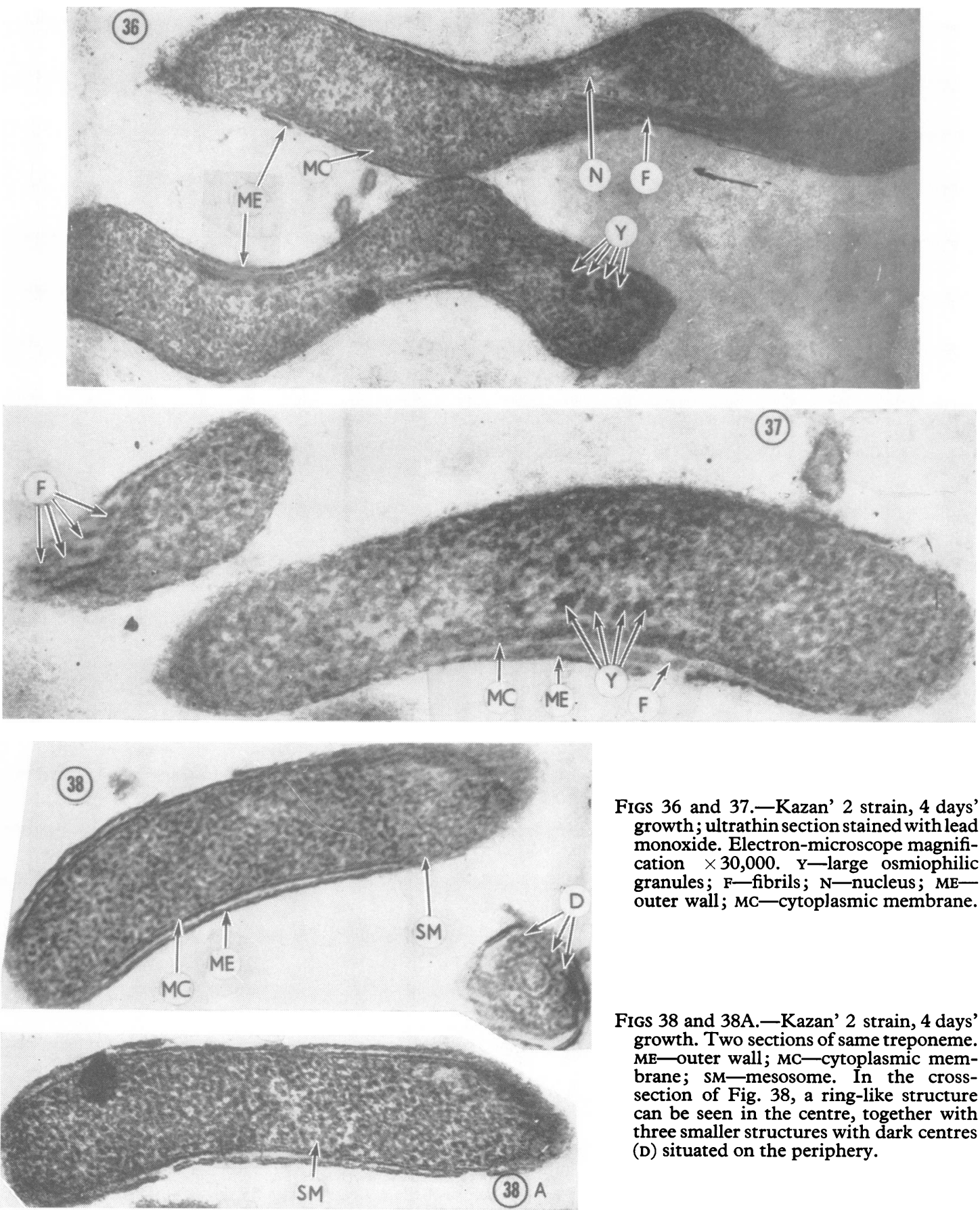

FIGs 36 and 37.-Kazan' 2 strain, 4 days' growth; ultrathin section stained with lead monoxide. Electron-microscope magnification $\times 30,000$. $\mathrm{Y}$-large osmiophilic granules; $\mathrm{F}$-fibrils; $\mathrm{N}$-nucleus; $\mathrm{ME}-$ outer wall; $\mathrm{MC}$-cytoplasmic membrane.

Figs 38 and 38A.-Kazan' 2 strain, 4 days' growth. Two sections of same treponeme. ME-outer wall; MC-cytoplasmic membrane; SM-mesosome. In the crosssection of Fig. 38, a ring-like structure can be seen in the centre, together with three smaller structures with dark centres (D) situated on the periphery. 

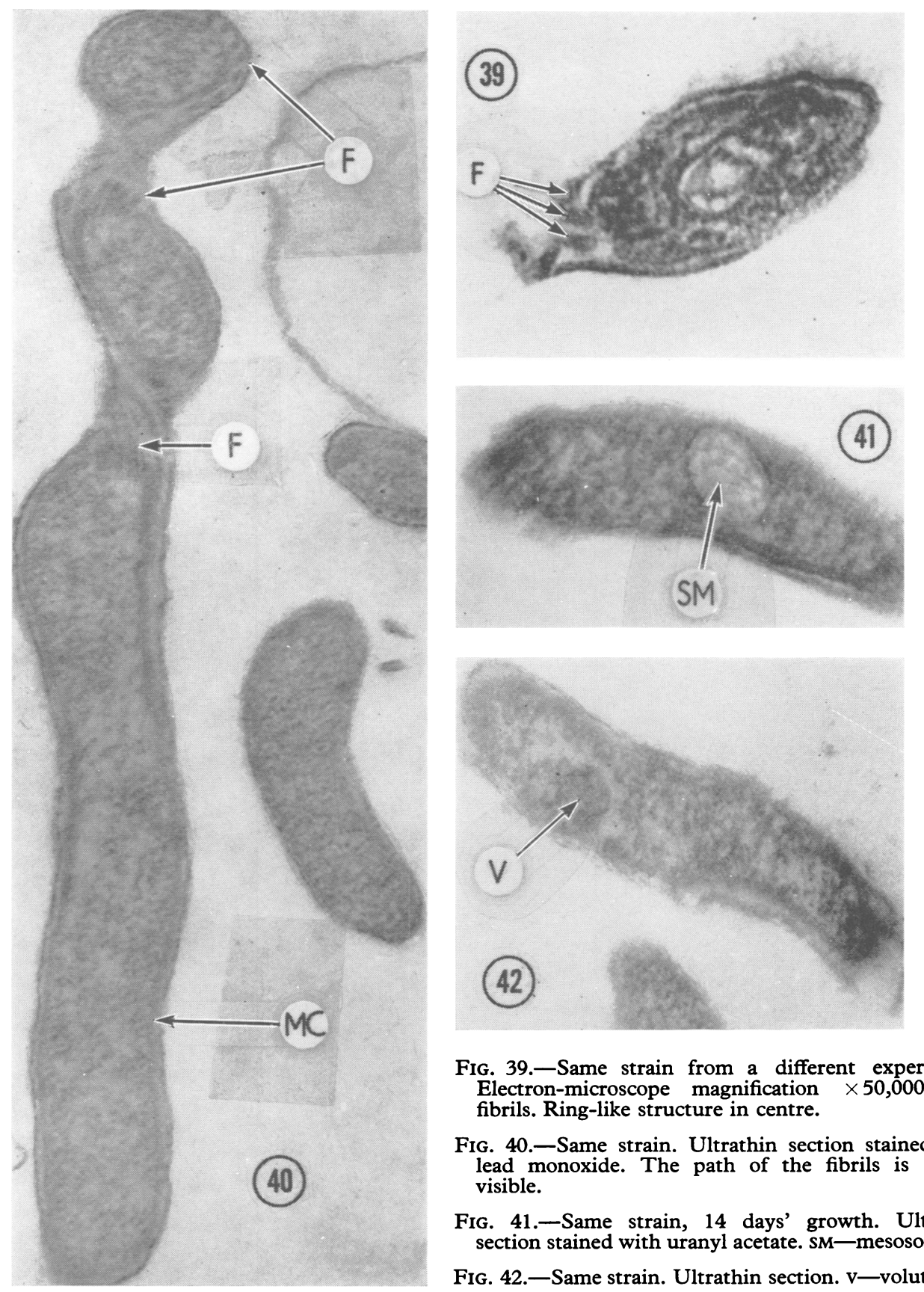

Fig. 39.-Same strain from a different experiment. Electron-microscope magnification $\times 50,000$. Ffibrils. Ring-like structure in centre.

FIG. 40.-Same strain. Ultrathin section stained with lead monoxide. The path of the fibrils is clearly visible.

FIG. 41.-Same strain, 14 days' growth. Ultrathin section stained with uranyl acetate. SM-mesosome.

FIG. 42.-Same strain. Ultrathin section. v-volutin? 

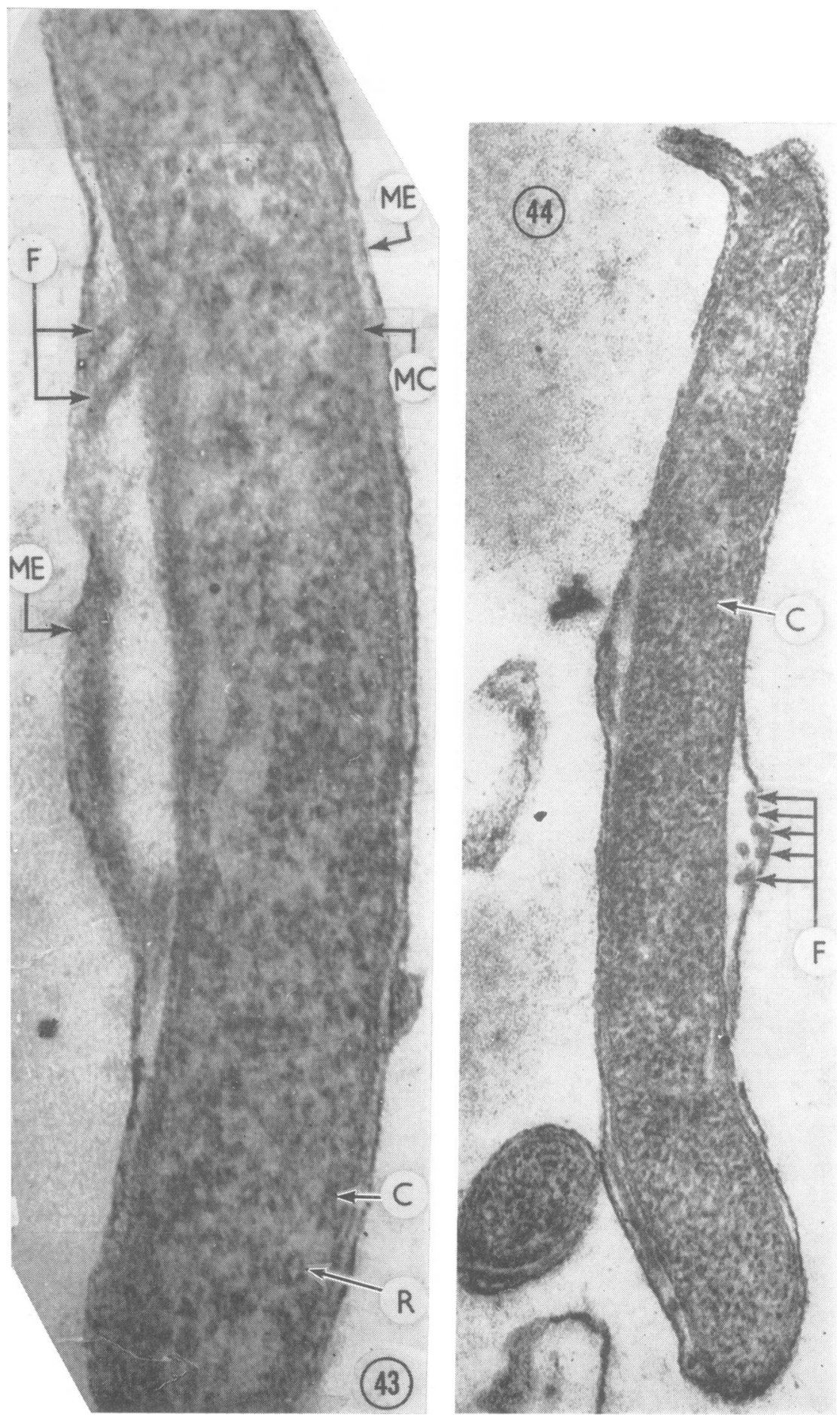


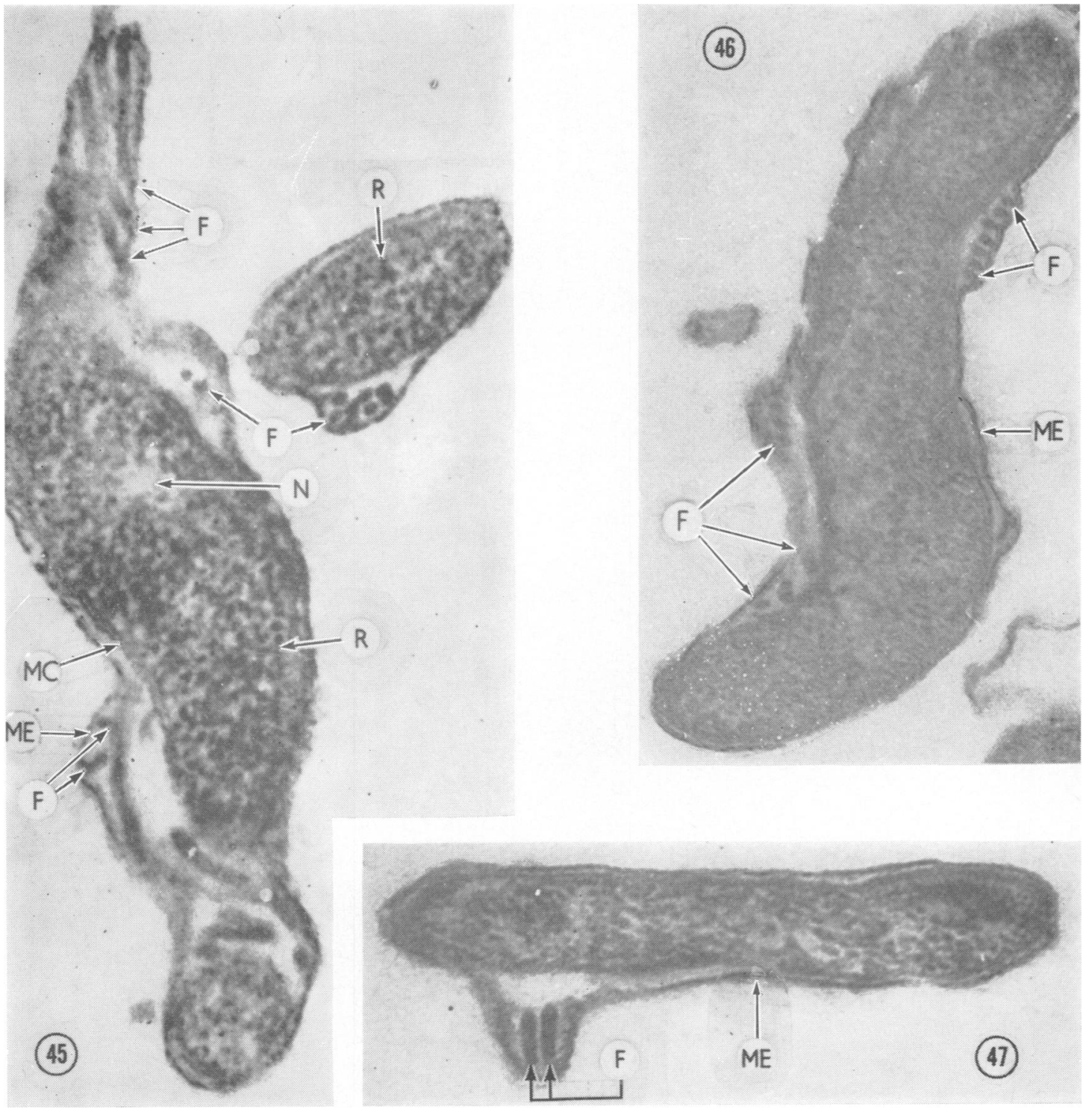

FIGs 44, 45, 46, and 47.-Kazan' 2 strain, 4 days' growth. Ultrathin sections stained with lead monoxide. Electron-microscope magnification (Fig. 44) $\times 40,000$; (Figs 45-47) $\times 30,000$.

FIG. 43.-Kazan' 2 strain. Ultrathin section stained with ME-outer wall; MC-cytoplasmic membrane; Flead monoxide. The outer wall (ME), obliquely and longitudinally-cut fibrils (F), cytoplasmic membrane (MC), ribosomal apparatus (R), and cytoplasm (C) are clearly visible. fibrils cut crosswise and longitudinally; $\mathrm{C}$-cytoplasm; $\mathrm{R}$-well-marked ribosomal apparatus; $\mathrm{N}$-nuclear vacuole. The outer wall stands out a long way above the fibrils.

In Fig. 46 the impression is given that the fibrils are situated on the inside of the outer wall. 


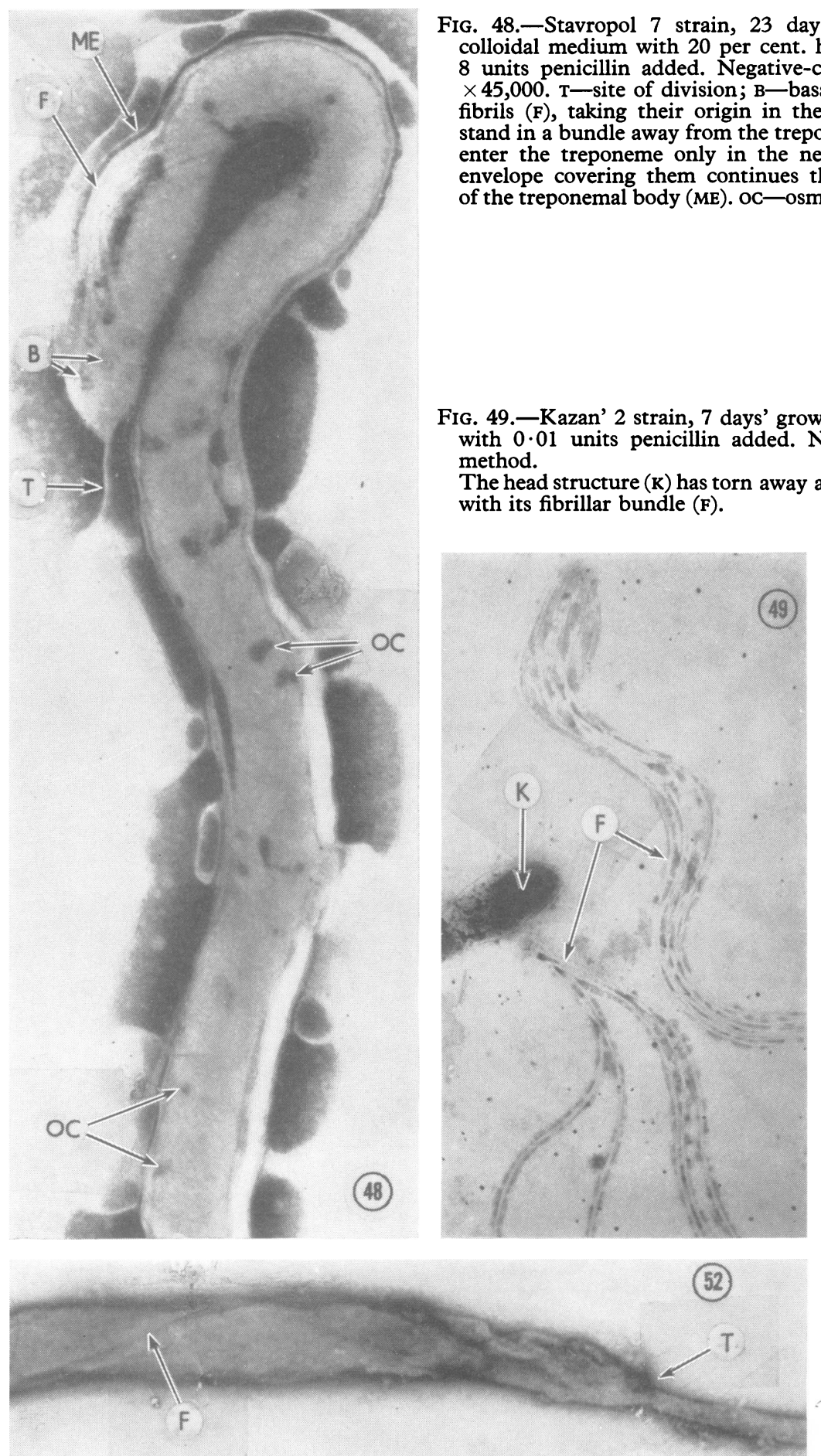

IG. 48.- Stavropol 7 strain, 23 days' growth on a units penicillin added. Negative-contrast method. (the basal granules, stand in a bundle away from the treponemal body and enter the treponeme only in the next segment. An envelope covering them continues the whole length of the treponemal body (ME). OC-osmiophilic cavities.

IG. 49.-Kazan' 2 strain, 7 days' growth on a medium with 0.01 units penicillin added. Negative-contrast method.

The head structure (K) has torn away and degenerated, with its fibrillar bundle (F). 

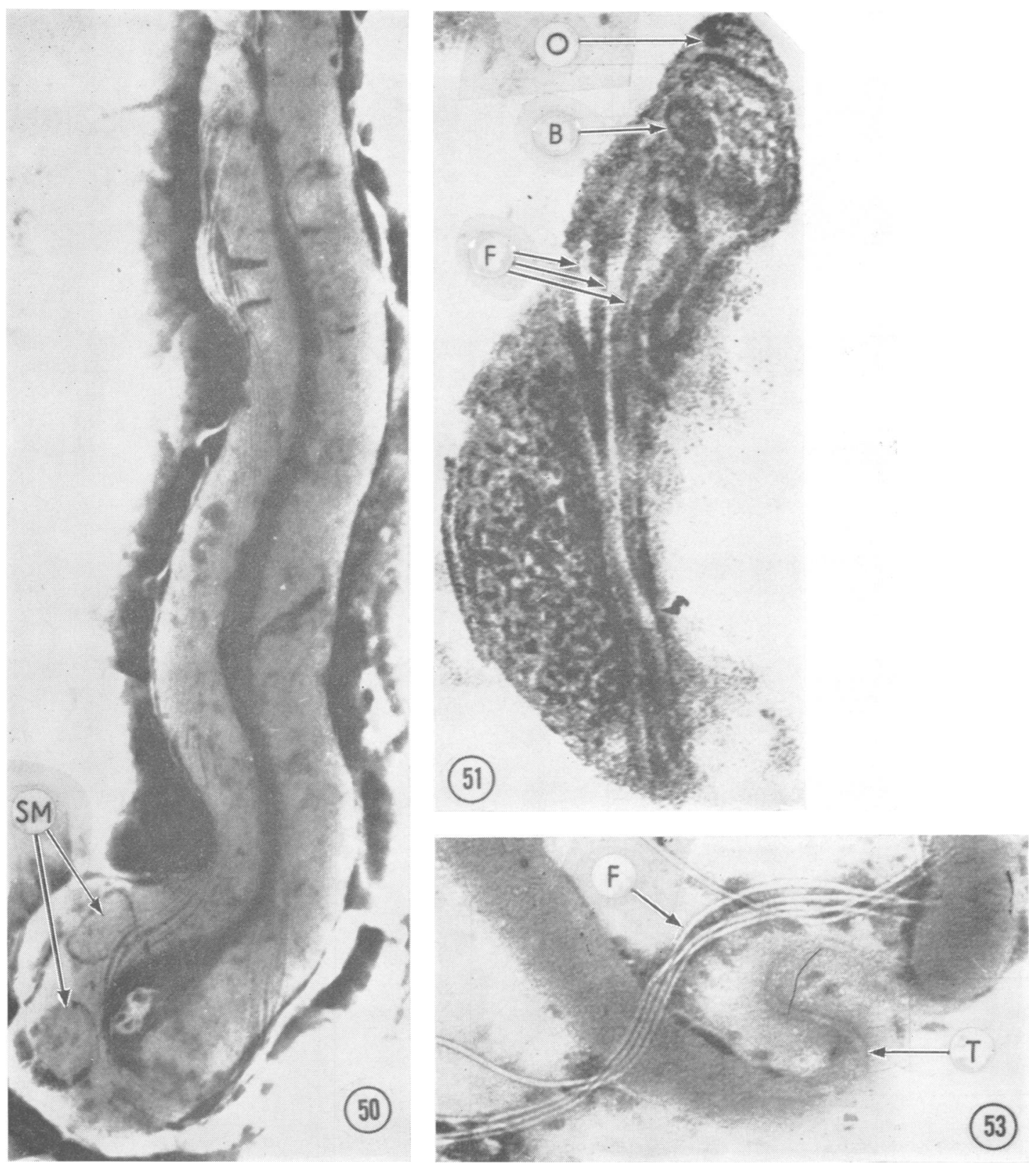

Fig. 50.-Kazan' 2 strain, 14 days' growth. Negativecontrast method. SM-expansions in the cytoplasm with granules.

FIG. 51.-Same strain. Ultrathin section stained with lead monoxide. B-basal granules; F-fibrils; ospongy mass.

FIg. 53.-Same strain as Fig. 49. At the site of division (T) a connecting piece in the shape of a thin tube has remained and at one end fibrils (F) are attached, 


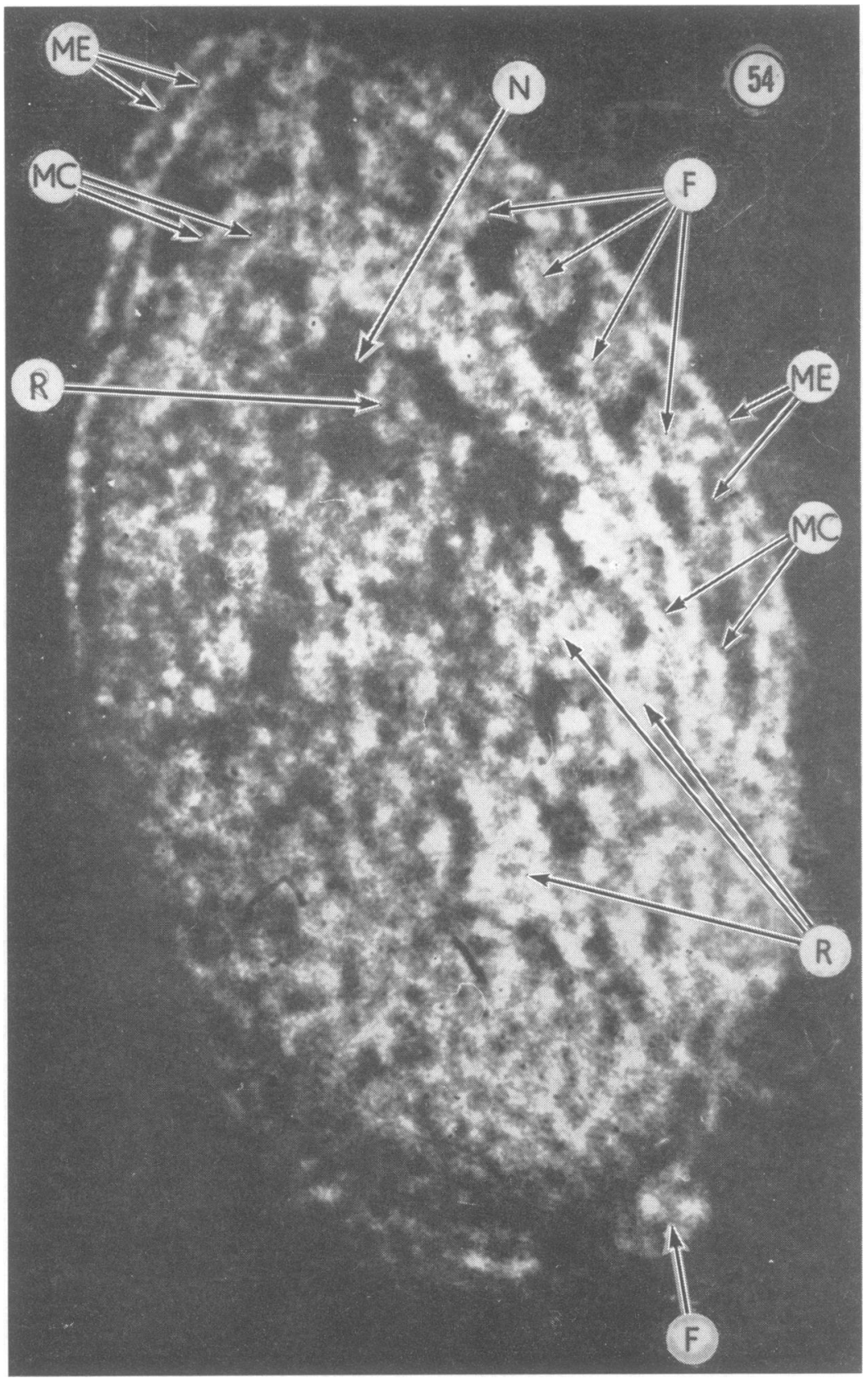



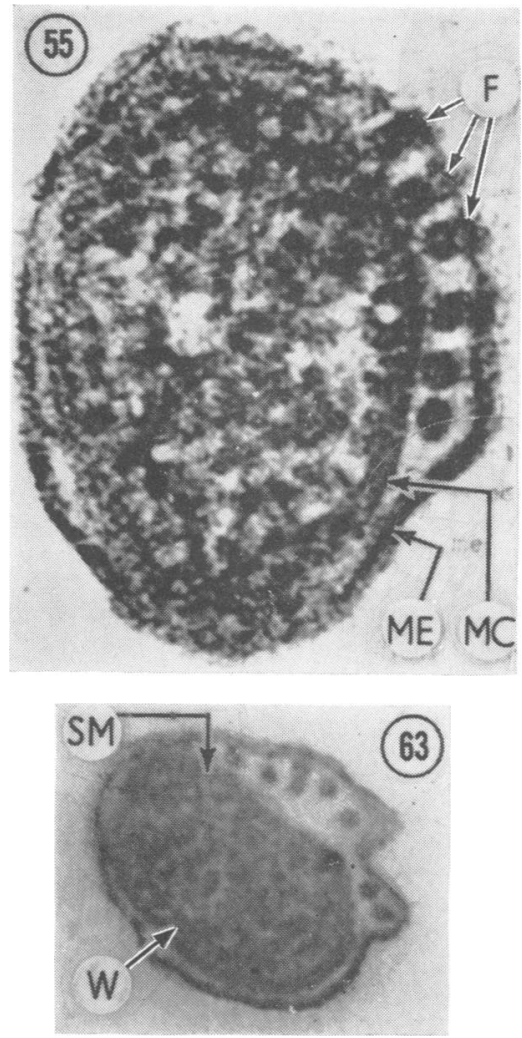
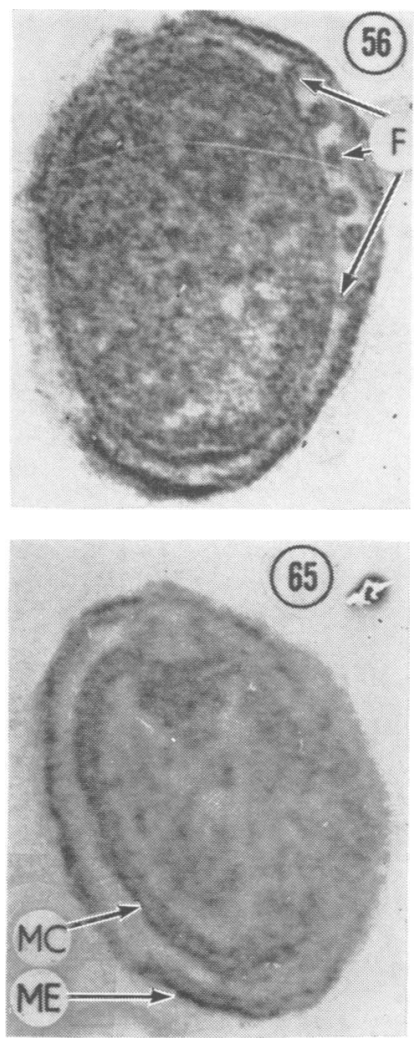
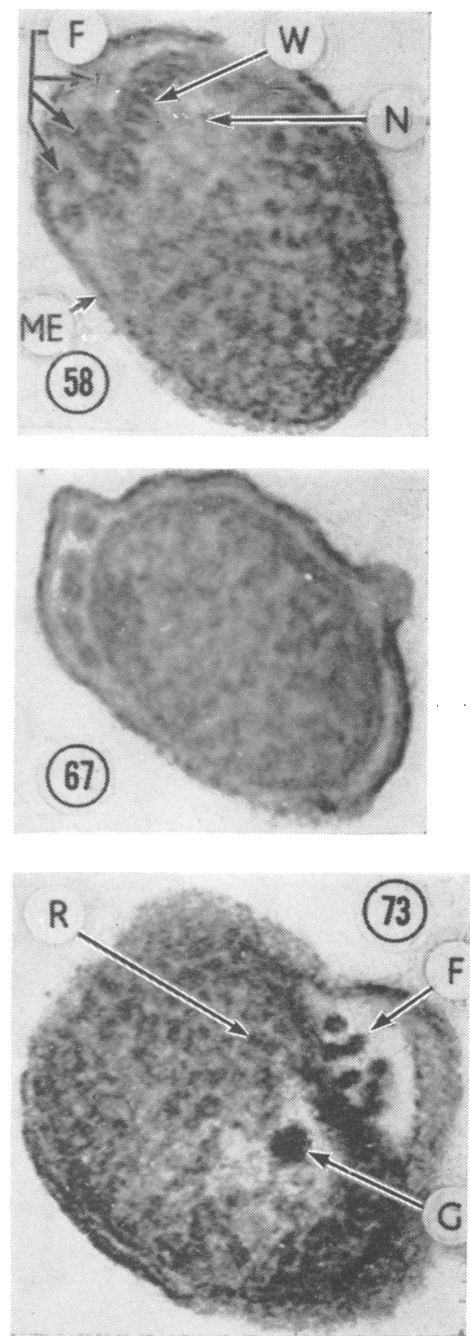

FIG. 54.-Kazan' strain, cross-section of $T$. pallidum, stained with lead monoxide. Actual electron-microscope magnification $\times 60,000$; photographic magnification $\times 540,000$. A negative has been made to show up more clearly the structure of the membranes and fibrillar apparatus. The two-layered structure of the outer wall (ME) is visible in the Figure, each layer consisting of separate particles. Less clear-cut but still quite visible is the two-layered structure of the cytoplasmic membrane (MC). The fibrils (F) look like lighter polygonal particles packed around the axis of the fibril. The ribosomal apparatus (R) has a structure similar to that of the fibrils. The nuclear vacuole is not clearly marked but takes the form of darker polygonal sectors $(\mathrm{N})$. 

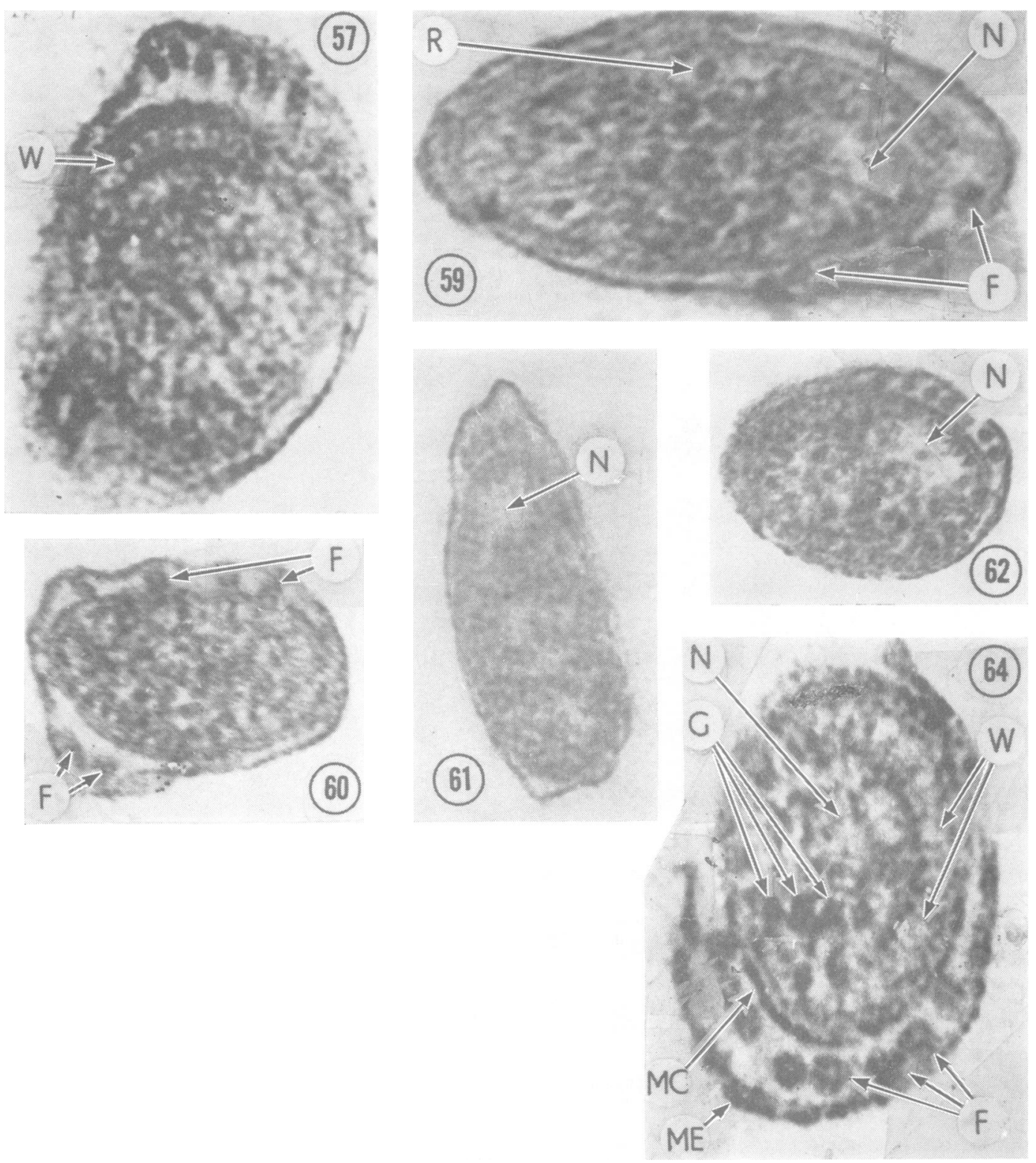

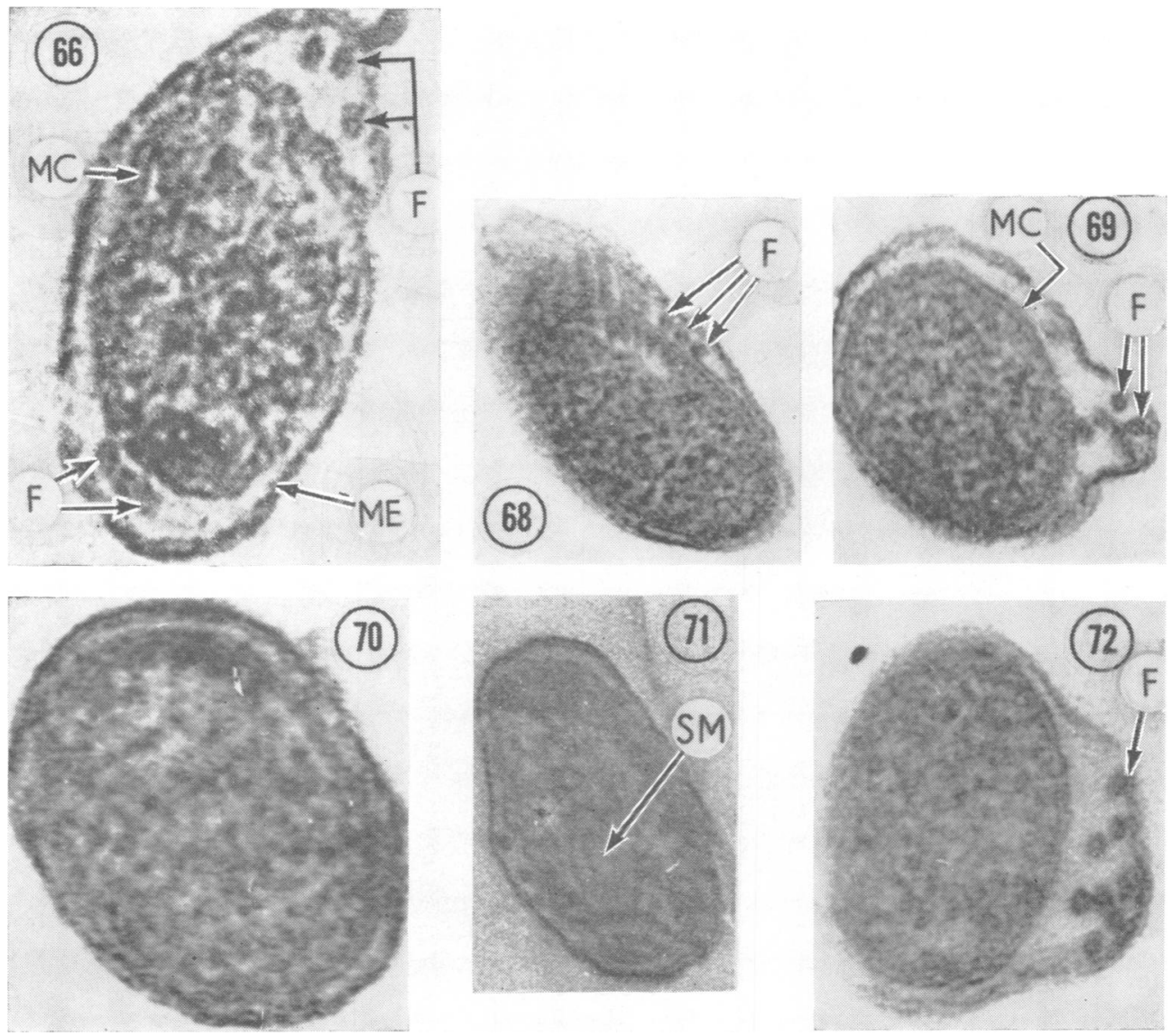

Figs 57, 59, 60, 61, 62, 64, 66, 68, 69, 70, 71, 72.Cross-sections stained with lead monoxide. Actual electron-microscope magnification $\times 60,000$; a greater enlargement has been achieved photographically. MEouter wall; MC-cytoplasmic membrane; F-fibrils; $\mathrm{N}$-nuclear vacuole; $\mathrm{R}$-ribosomal apparatus; $\mathrm{C}$ - cytoplasm; w-skein-like structures under the cytoplasmic membrane or else thickenings of the membrane. In Fig. 63 the hook-like depression with dark granules along its whole length (mesosome ?) under the cytoplasmic membrane contains a sector of skein-like structures (w). Figs 64 and 73 show large black granules (G) in the nuclear vacuole or close to it. In Fig. 66 the fibrils (F) are situated on both sides. In Fig. 70 the fibrils are not visible. In Fig. 71 there is a ring-like structure (SM) in the cytoplasm with a ring of smaller diameter inside it (mesosome). 


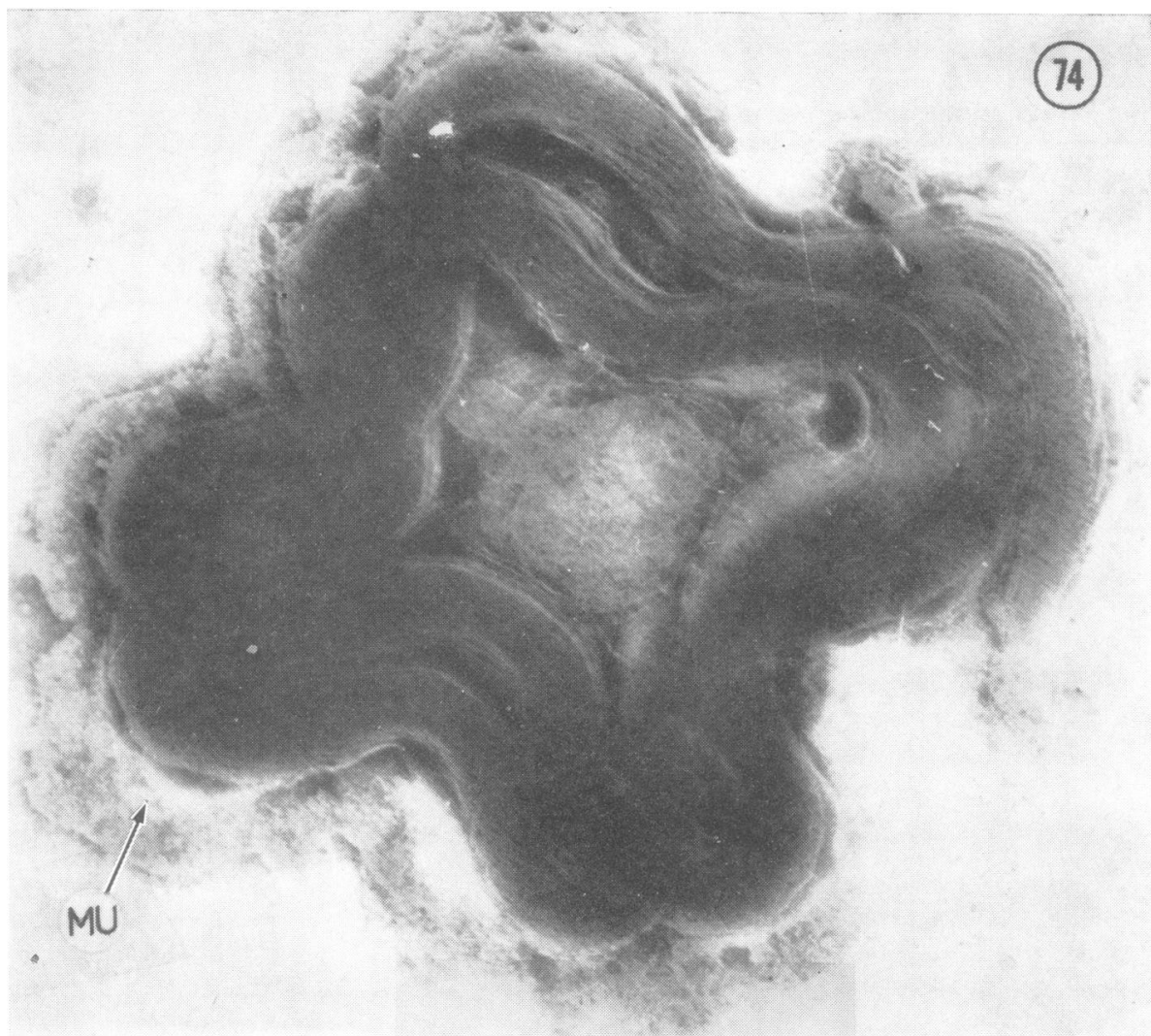

FIG. 74.-Nichols strain from a 7-day orchitis. Negativecontrast method. Electronmicroscope magnification $\times 40,000$, with subsequent photographic enlargement. This Figure illustrates how the treponeme is packed into the cyst. MU-mucus-like mass surrounding cyst.

Fig. 77.-Kazan' 2 strain, 4 days' growth. Ultrathin section stained with lead monoxide. $\times 40,000$. $M-$ wall of cyst; $\mathrm{ME}$-outer wall of treponeme; F-fibrils; $M C$ cytoplasmic membrane; c-cytoplasm; RL-roundlayered structures.

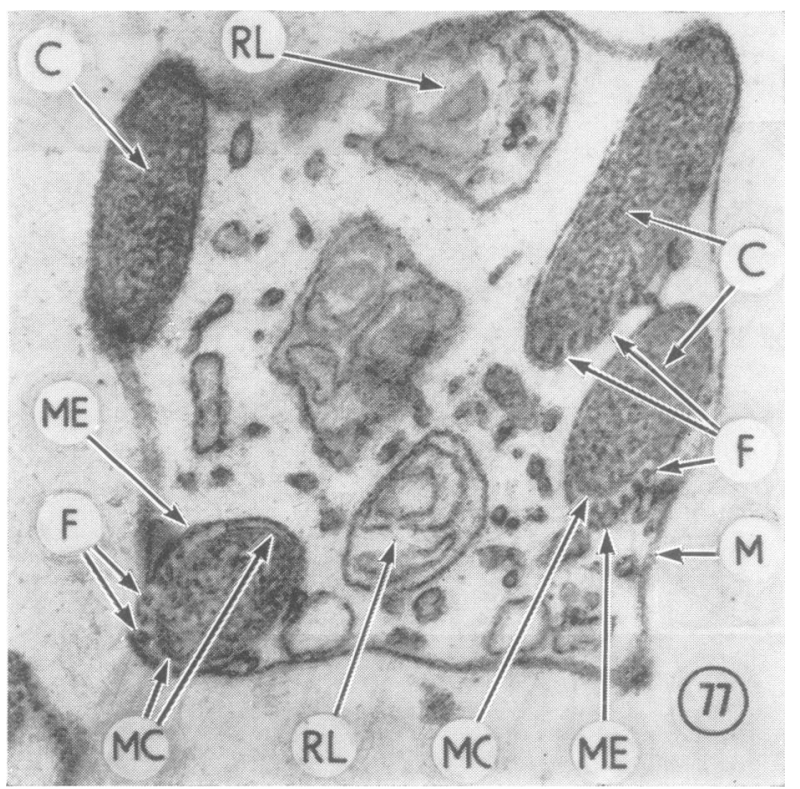



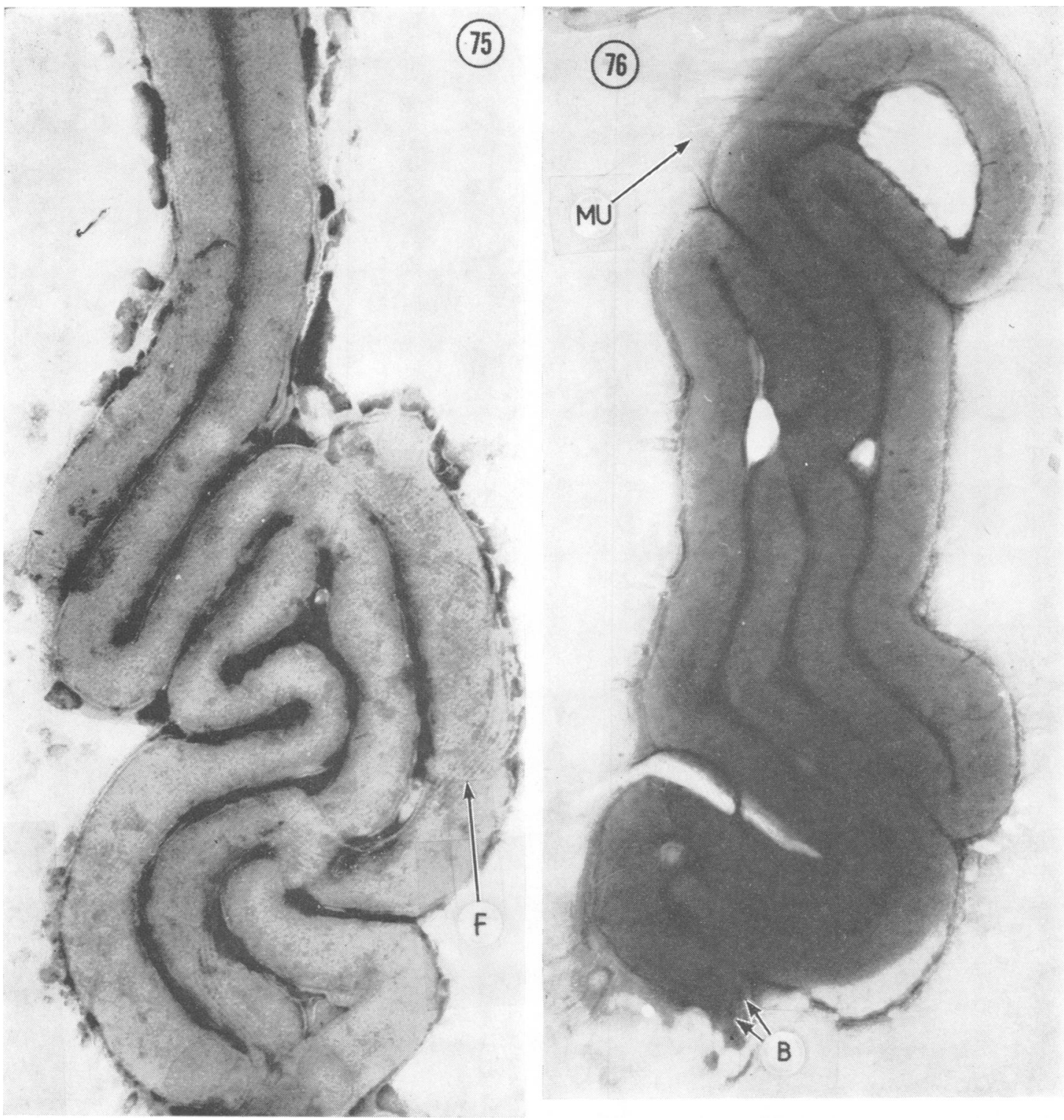

Figs 75 and 76.-Kazan' 2 strain, 4 days' growth. Negative-contrast method. $\times 38,000$. The treponeme is packed into a cyst surrounded by a mucus-like mass (MU). In Fig. 76 the basal granules (B) are clearly visible. 

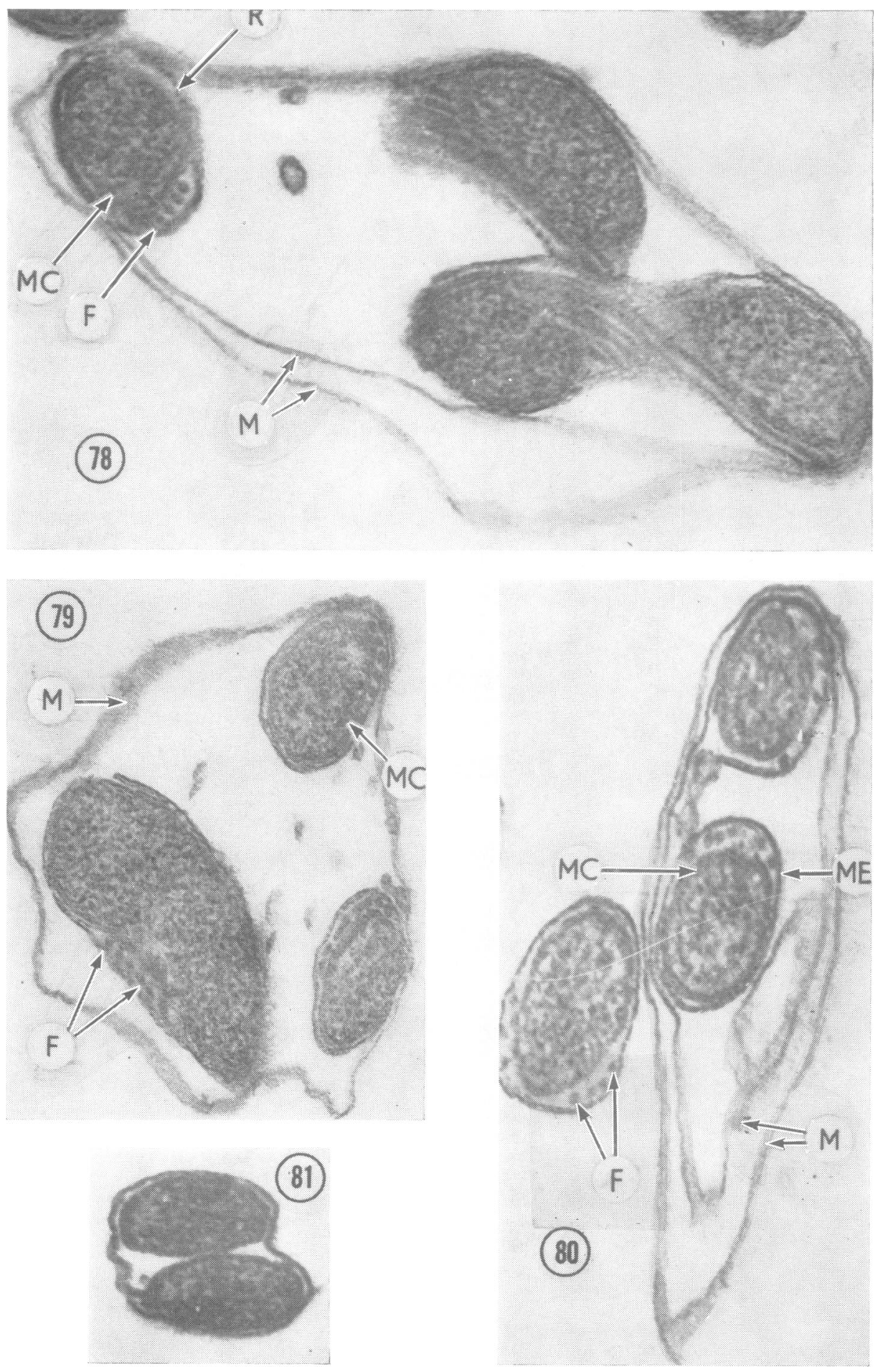

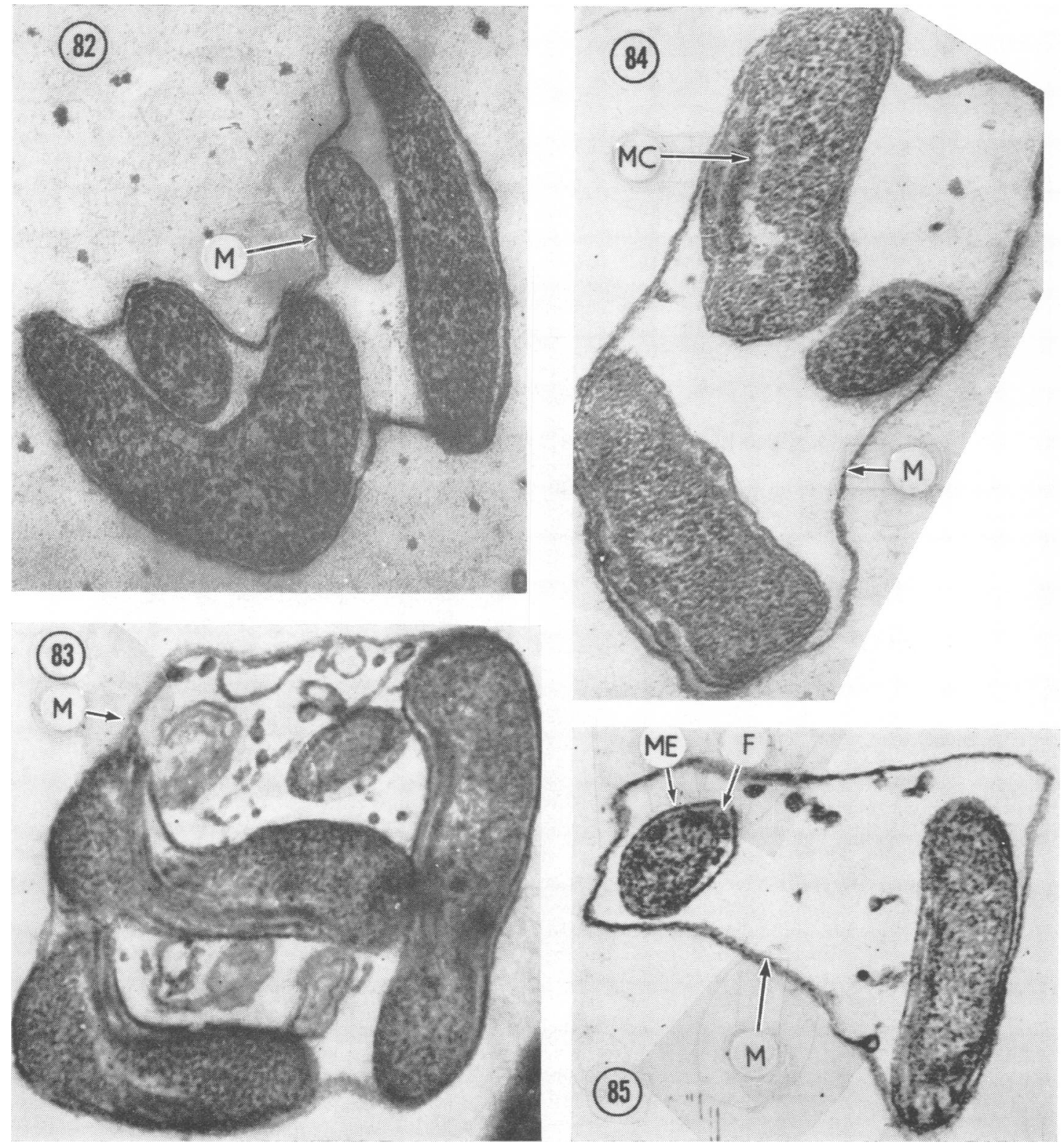

Figs 78, 79, 80, 81, 82, 83, 84, 85.-Kazan' 2 strain. Ultrathin sections. Key as for Fig. 77. The wellpreserved structure of the treponeme is everywhere visible: the path of the fibrils, the wholeness of the envelopes, and the structure of the cytoplasm. The cyst has an envelope of one or two layers and the outer wall of the treponeme is also preserved. 
of evidence is that the hook-like body represents mesosomes, while the ring-like structures are basal granules. Sometimes there is an out-pouching of the envelope in the outer wall (an area of destruction) and the cytoplasmic membrane under the spot dips down inside the cytoplasm (Fig. 67).

The encystment of treponemes is of immense interest. Under unfavourable conditions of existence for treponemes (lack of nutrients, the using up of nutrients for the process of division, after the addition of sera, particularly immune sera, and small quantities of penicillin, etc.), cysts are formed. Encystment begins with the treponeme "packing" itself to form a compact structure (Figs 75, 76) which then becomes covered with a mucous mass (Fig. 74MU). In any case Fig. 76 shows that some sort of fluid mass is leaving the treponeme and forming round it. Initially, encysted treponemes do not undergo any noticeable changes (Figs 77, 78, 79, 80, 81, 82, 83, 84, 85, 31 - part of a large cyst in which the path of the fibrils is very clearly visible). In Fig. 76 both head structures have joined together and the basal granules and fibrils are clearly visible. The envelope of the cyst is also formed from the outer wall of the treponeme, which quickly regenerates and again closely invests the treponeme. Possibly in these cases the way that the outer wall stands off from the treponeme through disturbance of osmotic pressure is sometimes taken for a cyst. In sections the cyst envelope $(M)$ can be seen when treponemes have been cut cross-wise and longitudinally and have their usual structure, with a well-preserved outer wall, cytoplasmic membrane, cytoplasm, and fibrils. In addition to this, in the cavity the remnants of cut fibrils can be seen and some round structures with two, three, or more layers, sometimes filled with a granular mass. These are possibly places of accumulation or storage of nutrient material. In places the cyst envelope is very wide and not clearly marked. This means that the envelope has been cut obliquely.

The sharply-marked structural elements of the treponeme and its complex and characteristic structure indicate that cysts are not a product of degeneration. In addition, in cultures where there are many cysts, they are very mobile, which is another argument against degeneration.

The explanations which we have given above for the structures found are suggestions rather than firm final statements, since their interpretation is extremely difficult, on the one hand because the study of treponemal structure by means of sections is new and no reliable evidence has appeared in the world literature, and on the other because it is difficult to explain the significance of each structure merely on the basis of a small part of the treponeme. To obtain a series of sections in particular directions and then to reconstruct the architecture of the organism is also extremely difficult. It is not yet possible to study the structure of whole treponemes, live, under high magnifications, and we cannot yet make wide use of the histochemical method combined with electron microscopy of treponemal sections. In such studies it is essential to compare the results of research by several methods. For that reason, authors who publish such material can only make suggestions as to the possible significance and function of a particular structure. The present authors, despite their inability to demonstrate the significance of particular structures, have published their findings because there have been few such studies, and it is hardly likely that an exhaustive and correct interpretation of the function of the structures will be forthcoming in the very near future.

As material accumulates and methods are further improved, other explanations of the findings may be given.

\section{Discussion}

It is now beyond dispute that the fibrils are attached to the basal granules and pass under the outer wall of the treponeme to come out on the opposite side, and also that the treponeme possesses an outer wall consisting of two electron dense layers and one electron transparent layer, and a cytoplasmic membrane also consisting of three layers, together with cytoplasm and a ribosomal apparatus. As for the nuclear vacuole it does not possess an envelope and its margins are polygonal. The vacuoles are not found along the whole length of the treponeme but only in individual sectors. The structure of the treponeme differs at different levels in cross-sections. In addition to two fibrillar bundles under the treponemal envelope in the cytoplasmic membrane, there is a thick bundle which fans out in the cytoplasm and apparently enters the nuclear vacuole. A treponeme may undergo transverse division in several places along its length, not merely in one place. Division is preceded by shedding the old fibrils and the formation of new basal granules and fibrils on either side of the site of division. The fine spiral filaments, as it were repeating the treponeme, which sometimes take origin in the head structure, are a bunch of fibrils still joined to the treponeme. There is still no really convincing explanation of the function of the round structures found in some parts of the treponeme which communicate with the space between the outer wall and the cytoplasmic membrane and with the external environment. In any case, these structures play an active part in the process of treponemal division and granule formation. Some of them appear to be mesosomes and some sporegranules. So far there is also no firm indication that an envelope of a mucous nature exists round the treponeme, although some micrographs give grounds for suspecting the presence of such envelope.

The existence of a porous mass in the head structures of the treponeme under the outer wall gives grounds for assuming that some substance contained in $T$. pallidum may be excreted. The 
possibility that treponemes possess a sexual mechanism of multiplication cannot yet be excluded.

Treponemal encystment is of great interest. It is impossible to agree with the opinion of Ryter and Pillot (1963) that cysts are a product of changes in osmotic pressure and of degeneration. As a result of changes in osmotic pressure, it is indeed possible to make the outer wall stand away from the treponemal body and to make the treponeme itself swell, but this produces only an outward, although sometimes close, likeness. In actual fact, under unfavourable conditions of existence, treponemes form real cysts as a method of persistent survival and multiplication, as occurs not infrequently among protozoa.

The fact that cysts are not a product of degeneration is shown by their appearance under various unfavourable conditions, the fact that they roll up into skeins (packing themselves tight, as it were), the formation of mucus round the envelope (the envelope being formed from the outer wall, which is then regenerated), the preservation in cross-sections of the characteristic structure with all envelopes, fibrils, etc., present, and so on. An important proof of the viability of cysts is their motility, as seen under dark-field and phase-contrast microscopy. When transfers are made from cultures containing cysts and almost no ordinary spiral forms, growth of ordinary spiral forms occurs.

The fact that, in the the experiments by Ryter and Pillot, spheroids (cysts) are quickly formed under experimental conditions after exposure to various factors is not a sign of degeneration but a proof that their formation is above all a protective device-skein formation, and the formation of a protective mucoid envelope. This phenomenon is widespread in nature. The huge majority of cysts in protozoa, according to Dogel' (1951), are a means of protecting their content against unfavourable conditions, but some of them are designed rather to ensure a long period of rest. Later, depending on conditions and when the harmful exposure is past, protective cysts may become multiplication cysts. They are not of a purely protective character but also serve for multiplication. Treponemal cysts change into small segments (granule-spores) with two-layered envelopes, and these later develop into the usual spiral form of treponeme. The formation of sexual cysts, e.g. in Sporozoa, is accompanied by the formation of an extra system of envelopes, clearly showing, among other things, that these are protective envelopes of the type of resting cysts (Dogel', 1951).

The experiments carried out by Pillot (1965) leading to the formation of cysts have long been well known to protozoologists. Thus, Dogel' writes that the factors causing encystment may be varied. Encystment may depend on temperature, the concentration of substances dissolved in water, evaporation of water, the accumulation in it of harmful products of metabolism, an oxygen deficit, lack of food, or a combination of several of these factors. In some instances protozoa undergo temporary encystment in order to complete the process of reorganizing their nuclear apparatus. The main factor regulating cyst formation is the exhaustion of food in the environment. In a very dense culture which is kept constantly supplied with nutrients, rest cysts are not formed, whereas multiplication cysts are formed quite frequently.

All these conditions also apply to encystment in treponemes and several other factors may be adduced in addition.

It is noteworthy that the head (terminal body) has a somewhat different structure from the treponeme as a whole and differs in cultured and pathogenic treponemes.

\section{Conclusions}

(1) The existence of an outer wall, a cytoplasmic membrane, cytoplasm, basal granules, a fibrillar apparatus, a nuclear vacuole, and ribosomes in $T$. pallidum has been clearly demonstrated.

(2) Each fibrillar bundle consists of two to eight fibrils attached to the basal granules.

Basal granules and fibrils are formed at the site of division.

(3) The main method of multiplication of treponemes under favourable conditions is transverse fission, but no final proof has been given that other forms of multiplication (granules, cysts) should be ruled out. No evidence was found that a sexual process occurs in treponemes.

(4) The available material points to the existence of mesosomes in the treponeme and of a spongy mass of some sort at its ends.

(5) Treponemal cysts are a form of persistent survival and multiplication.

(6) On the basis of the data obtained some corrections should be made in the definition of $T$. pallidum as a species quoted by Breed, Murray, and Smith (1957).

\section{Summary}

Further electron microscope studies of ultrathin sections of $T$. pallidum are reported. Treponemes were obtained from infected humans and from rabbits infected with various strains (Nichols, 
Central Institute for Research on Skin and Venereal Diseases, and Budapest), and cultured treponemes (Kazan' 2, 5 and 7) were also studied.

The existence has been demonstrated of an outer wall, cytoplasmic membrane, cytoplasm, and two fibrillar bundles attached to basal granules. The path of the fibrils, the structure of the mesosomes, the nuclear vacuole, head structures, etc., are described. The process of division is described and the existence of cysts as a form of survival and multiplication of $T$. pallidum is demonstrated. The complexity of structure of $T$. pallidum and the inadequacy of our present knowledge of its structure and biology are emphasized.

\section{REFERENCES}

Breed, R. S., Murray, E. G. D., and Smith, N. R. (1957). "Bergey's Manual of Determinative Bacteriology", 7th ed. Williams and Wilkins, Baltimore.

Dogel', V. A. (1951). "Obshchaya protistologica." Sovetskaja nanka, Moscow. (1965. "General Protozology", English translation from 2nd Russian edition, 1962. Clarendon Press, Oxford.)

Horwitz, D., and Fors, D. (1962). "Structure and Function of the Cell." MIR, Moscow, 1964.

Ovcinnikov, N. M., and Delektorskij (1965). "Anatomy of Treponema pallidum." WHO/VDT/RES/79.65.

Pillot, J. (1965). Thèses presentées à la faculté des sciences de l'université de Paris pour obtenir le grade de docteur des sciences naturelles, Lons le Saunier.
Ryter, A., and Pillot, J. (1963). Ann. Inst. Pasteur, 104, 496.

Valentine, R. C., and Horne, R. W. (1962). In "The Interpretation of Ultrastructure", Symposia int. Soc. Cell Biology, vol. 1, ed. R. J. C. Harris, p. 263. Academic Press, London.

\section{Une étude additionnelle des sections ultra-minces du Treponema pallidum au microscope électronique \\ RÉSUMé}

Des études additionnelles au sujet des sections ultraminces des $T$. pallidum sont rapportées. Les tréponèmes avaient été obtenus d'humains malades et de lapins infectés par diverses souches (Nichols, Institut Central de Recherches au sujet des maladies de la peau et des maladies vénériennes, et Budapest); les tréponèmes cultivés (Kazan, 2, 5, 7) ont été aussi etudiés.

L'existence d'une paroi, d'une membrane cytoplasmique, de cytoplasme, et deux faisceaux composés de fibrilles attachées aux granules basiques a été demontrée. Le trajet des fibrilles, la structure des mésosomes, le vacuole du noyau, la structure des têtes, etc., sont décrits. Le processus de division est décrit et l'existence des kystes pour la survivance et la multiplication du $T$. pallidum est demontrée. La complexité des structures $\mathrm{du} T$. pallidum et l'insuffisance de nos connaissances à l'heure actuelle de sa structure et de sa biologie sont soulignées. 